Article

\title{
Transient Temperature Calculation and Multi-Parameter Thermal Protection of Overhead Transmission Lines Based on an Equivalent Thermal Network
}

\author{
Jian $\mathrm{Hu}$ *, Xiaofu Xiong, Jing Chen, Wei Wang and Jian Wang \\ State Key Laboratory of Power Transmission Equipment \& System Security and New Technology, \\ School of Electrical Engineering, Chongqing University, Shapingba District, Chongqing 400044, China; \\ xxfcqu@foxmail.com (X.X.); wrxrk@foxmail.com (J.C.); ww0326@outlook.com (W.W.); \\ wangjiancqu@foxmail.com (J.W.) \\ * Correspondence: exphujian@cqu.edu.cn; Tel.: +86-18875207719
}

Received: 17 November 2018; Accepted: 22 December 2018; Published: 26 December 2018

\begin{abstract}
The overload degree of a transmission line is represented by currents in traditional overload protection, which cannot reflect its safety condition accurately. The sudden rise in transmission line current may lead to cascading tripping under traditional protection during power flow transfer in a power system. Therefore, timely and accurate analysis of the transient temperature rise of overhead transmission lines, revealing their overload endurance capability under the premise of ensuring safety, and coordination with power system controls can effectively eliminate overloading. This paper presents a transient temperature calculation method for overhead transmission lines based on an equivalent thermal network. This method can fully consider the temperature-dependent characteristics with material properties, convective heat resistance, and radiation heat and can accurately calculate the gradient distribution and response of the conductor cross-section temperature. The validity and accuracy of the proposed calculation method are verified by a test platform. In addition, a multi-parameter thermal protection strategy is proposed on the basis of the abovementioned calculation method. The protection can adequately explore the maximum overload capability of the line, and prevent from unnecessary tripping to avoid the expansion of accidents. Finally, the validity of the proposed protection is verified by the modified 29-bus system.
\end{abstract}

Keywords: overhead transmission line; overload cascading tripping; equivalent thermal network; transient temperature; thermal protection

\section{Introduction}

Large-scale blackouts have constantly resulted in catastrophic consequences. How to effectively avoid power grid cascading tripping has been a research focus all over the world [1,2]. Removal of a single faulty line or equipment causes power grid structural changes, thereby resulting in power flow transfer and sudden rise in the currents of several transmission lines [3]. Lack of information exchange between security and operation time of protection will lead to undesired results [4]. Traditional overload protection depends on a pre-set current value. When the current flow (non-fault current) is greater than the pre-set value, the relay protection trips immediately and further cause a new sequence of power flow transfers which will eventually develop into a cascading tripping event. In recent years, overload protection has boosted the development of cascading tripping in several blackouts, such as the USA/Canada blackout on 14 August 2003, the Italian blackout on 8 September 2003, and the two power outages in India on 30 and 31 July 2012 [5-7]. 
The electrical and mechanical properties, strength loss, and sagging of overhead transmission lines during overloading are influenced by conductor temperature and overload duration [8-10]. The conductor temperature can be a more accurate reflection of the safety condition of transmission lines than current. Two main approaches based on conductor temperature are used to characterize the overload degree of the line. The first one is by gathering real-time data from conductor temperature measuring devices installed on the line as the operating criterion for overload protection [11,12]. The second is by adaptively adjusting the setting value of protection delay time based on a dynamic thermal line rating (DTLR) calculation model [13-16].

The measured temperature cannot completely represent the actual maximum temperature for long-distance lines that run across multiple meteorological regions given the limited location and quantity of conductor temperature measuring devices. Temperature gradient distribution and different responses, which are influenced by factors, such as skin effect, external forced convection, and various twisted materials, exist in the conductor cross-section. Moreover, existing temperature measuring devices can only collect the surface temperature of the conductor, and its sampling interval, data transmission, and processing speed cannot satisfy the time requirements of actual protection strategies.

DTLR calculation models are mostly constructed on the basis of IEEE and CIGRE standards [17,18], which simplify the heat transfer of conductor and treat the conductor as an isothermal body to obtain its surface or average temperature. Although DTLR models can reflect the electro-thermal coupling effect of transmission line under steady ambient meteorological conditions, it cannot characterize the difference in conductor inner transient temperature rise responses [19-21].

A serious deviation occurs when the safety assessment and protection of overload transmission lines are set on the basis of a single point temperature. Therefore, there is a need to establish a transmission line transient temperature calculation method that can not only reflect the gradient distribution and transient responses of conductor cross-section temperature, but also meet the calculation time requirements of protection, which is of great significance to accurately assess the safety of transmission lines.

So far, numerous studies have been conducted on conductor transient temperature calculation, which considers the structural characteristics of a conductor with several materials that can affect heat transfer [22-28]. For example, in [23-25], conductor temperature calculation model was established by thermal circuit model on the basis of thermal-electrical analogy theory. Full consideration of heat transfer characteristics of different materials, the model put the analysis of heat transfer process into the solution of electrical circuit to grasp the operation of overhead transmission line conveniently and rapidly. By contrast, this model ignores the temperature-dependent properties of several conductor parameters during the dynamic thermal process. Radial or axial temperature calculation models in the form of state equation were established based on thermal equilibrium principle under the condition of constant environment temperature and constant humidity in [26-28]. Whereas, the radial and axial temperature distributions of a conductor were obtained under an ideal natural convective heat transfer condition, and the calculation methods demonstrate a remarkable precision. However, transmission lines mostly operate in a complex environment, which corresponds to a forced convective heat transfer situation. Several factors, such as wind and solar radiation, affect the heat transfer of transmission lines. Thus, the temperature calculation method obtained from ideal natural convection conditions cannot accurately and comprehensively reflect the influence of ambient meteorological environment on the transient temperature rise response of the conductor.

Several researchers have used a finite element model to solve the transient temperature field of conductors [29]. However, the accuracy of the finite element model depends on grid sizes and structure division. The finite element model has large computation and poor real-time calculation capacity and cannot satisfy the time requirements of a power system protection. Thus, this model is unsuitable for practical projects. 
Through the above analysis, this paper proposes a transient temperature calculation method for overhead transmission lines based on an equivalent thermal network (ETN). The ETN completely considers the influence of the external environment on the radial and circumferential heat transfer of a conductor cross-section. The calculation method fully considers the influence of temperature-dependent characteristics of material, convective heat resistance, and radiation heat on the temperature difference in the conductor cross-section by adopting nonlinear iteration. Moreover, the proposed transient temperature calculation method is applied to a multi-parameter thermal protection (MPTP) of transmission lines. A temperature-time integral of the MPTP can effectively indicate the transient temperature rise and its thermal incubation effect. The protection can adequately prolong the operation time in a safe way. Consequently, line overloading can be eliminated by coordination with the power system control measures, and large-area cascading tripping accidents can be effectively avoided.

The remainder of this paper is organized as follows: in Section 2, the ETN characterizing the transient temperature of overhead transmission lines is established. In Section 3, the transient temperature calculation method based on the ETN is proposed. In Section 4, the validity and accuracy of the ETN and calculation method are verified by the transmission line test platform. In Section 5, the realization and functions of the MPTP based on the transient temperature calculation of transmission lines are given. In Section 6, the modified 29-bus system (Hydro Quebec) is adopted to verify the rationality and applicability of the proposed protection strategy. Finally, the conclusions of this paper are presented in Section 7.

\section{ETN Modeling of Overhead Transmission Lines}

\subsection{Heat Transfer Analysis of Overhead Transmission Line Cross-Section}

At present, the commonly used conductor for transmission lines are aluminum conductor steel-reinforced (ACSR) [30], which consist of multiple twisted steel core and aluminum layers. In Figure 1, the existing temperature calculation models of overhead transmission lines mostly consider the entire conductor as an isothermal body or only considers the radial heat transfer path of the conductor cross-section, and each radial layer is regarded as an isothermal body $[23,24,26,27]$.

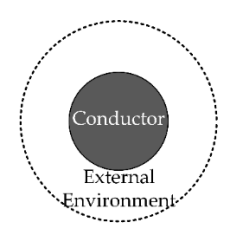

(a)

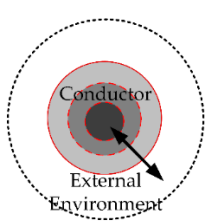

(b)

Figure 1. Simplified heat transfer analysis of the overhead transmission line cross-section. (a) Conductor is considered isothermal; (b) Only the radial heat transfer path is considered.

However, different zones of the conductor cross-section are differently influenced by forced convective heat and radiation heat transfer in actual operations as demonstrated in Figure 2. There are temperature differences between the windward, upper surface, leeward, and lower surface zones of the conductor cross-section.

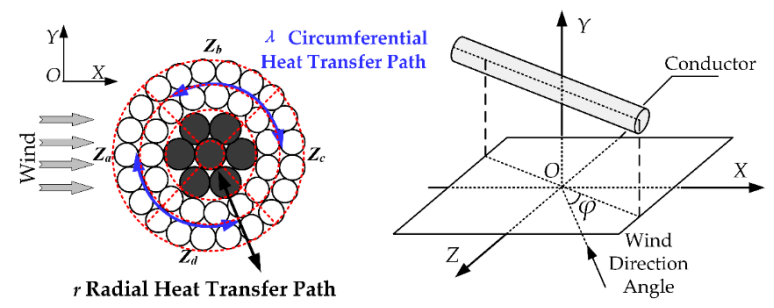

Figure 2. Heat transfer analysis and geometric division of overhead transmission line cross-section considering radial and circumferential heat transfer paths. 


\subsection{ETN of Overhead Transmission Lines}

The physical variables in heat transfer have a similar correspondence with the physical variables in electricity. Thus, thermal-electrical analogy can be used to simulate the heat transfer process [31]. The conductor cross-section is divided into $n$ layers (the $n$th layer is the central layer) in the radial direction. The heat loss generated by each layer of conductor is the heat source, and the heat transfer of heat flux in each physical layer can be equivalent to the thermal network. Where each physical layer is represented by a pair of $R$ and $C$, to obtain the ETN by considering the radial and circumferential heat transfer paths of the conductor cross-section, as depicted in Figure 3.

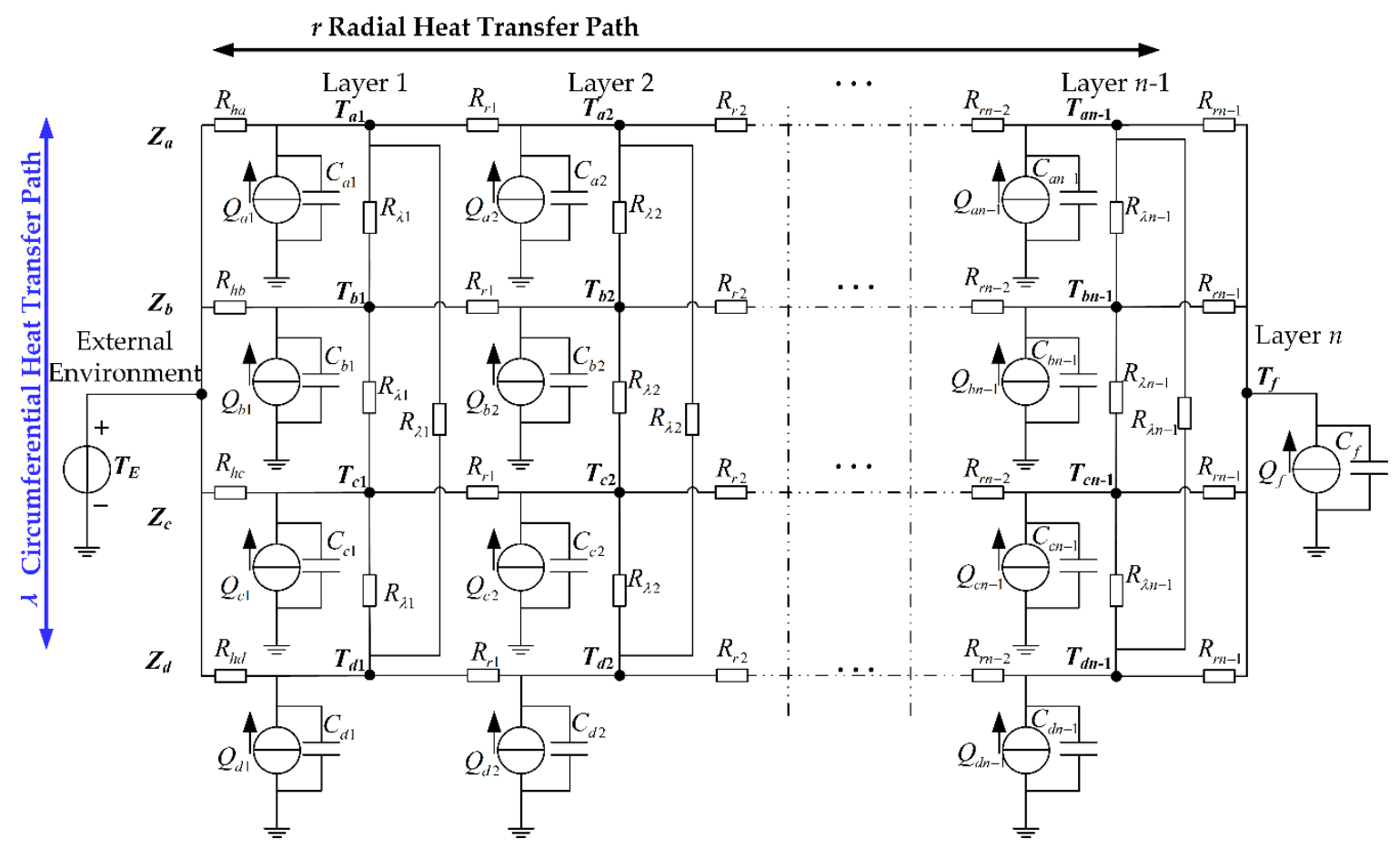

Figure 3. ETN of the overhead transmission lines considering radial and circumferential heat transfer paths.

In Figure $3, T_{E}$ and $T_{f}$ denote the ambient temperature and temperature of the $n$th layer of the conductor, respectively. $T_{a 1}, T_{a 2}, \ldots, T_{a n-1}$ denote the temperature of the first layer (surface) to the $(n-1)$ th of the conductor in the windward zone $Z_{a}$. Similarly, $T_{b 1}, T_{b 2}, \ldots, T_{b n-1}, T_{c 1}, T_{c 2}, \ldots, T_{c n-1}$, and $T_{d 1}, T_{d 2}, \ldots, T_{d n-1}$ denote the temperature of each layer of the conductor in the upper surface zone $Z_{b}$, leeward zone $Z_{c}$, and lower surface zone $Z_{d} . C_{a 1}, \ldots, C_{a n-1}, C_{b 1}, \ldots C_{b n-1}, C_{c 1}, \ldots, C_{c n-1}$, and $C_{d 1}, \ldots, C_{d n-1}$ are the equivalent thermal capacities in the corresponding position of each layer of the conductor. $Q_{a 1}, Q_{a 2}, \ldots, Q_{a n-1}, Q_{b 1}, Q_{b 2}, \ldots, Q_{b n-1}, Q_{c 1}, Q_{c 2}, \ldots, Q_{c n-1}$, and $Q_{d 1}, Q_{d 2}, \ldots, Q_{d n-1}$ represent the heat flux in the conductor layer, in which $Q_{a 1}, Q_{b 1}, Q_{c 1}$, and $Q_{d 1}$ include the heat flux variation in the conductor surface given the joint action of current and radiation. $Q_{f}$ and $C_{f}$ denote the heat flux and capacity of the $n$th layer (central layer), correspondingly. $R_{r 1}, R_{r 2}, \ldots, R_{r n-1}$ are the radial thermal resistances between the conductor layers. $R_{\lambda 1}, R_{\lambda 2}, \ldots, R_{\lambda n-1}$ denote the circumferential thermal resistances of each layer between zones $Z_{a}$ and $Z_{d} . R_{h a}, R_{h b}, R_{h c}$, and $R_{h d}$ represent the thermal convection resistances between each zone of the conductor surface and environment. 
Kirchhoff's current law and Kirchhoff's voltage law can be analogized to the thermal network. The time domain differential equations of nodes in the ETN can be expressed as Equations (1)-(3):

$$
\begin{gathered}
\left\{\begin{array}{l}
C_{a 1} \frac{d T_{a 1}}{d t}=Q_{a 1}-\frac{T_{a 1}-T_{E}}{R_{h a}}-\frac{T_{a 1}-T_{a 2}}{R_{r 1}}-\frac{T_{a 1}-T_{d 1}}{R_{\lambda 1}}-\frac{T_{a 1}-T_{b 1}}{R_{\lambda 1}} \\
C_{b 1} \frac{d T_{b 1}}{d t}=Q_{b 1}-\frac{T_{b 1}-T_{E}}{R_{h b}}-\frac{T_{b 1}-T_{b 2}}{R_{r 1}}-\frac{T_{b 1}-T_{a 1}}{R_{\lambda 1}}-\frac{T_{b 1}-T_{c 1}}{R_{\lambda 1}} \\
C_{c 1} \frac{d T_{c 1}}{d t}=Q_{c 1}-\frac{T_{c 1}-T_{E}}{R_{h c}}-\frac{T_{c 1}-T_{c 2}}{R_{r 1}}-\frac{T_{c 1}-T_{b 1}}{R_{\lambda 1}}-\frac{T_{c 1}-T_{d 1}}{R_{\lambda 1}} \\
C_{d 1} \frac{d T_{d 1}}{d t}=Q_{d 1}-\frac{T_{d 1}-T_{E}}{R_{h d}}-\frac{T_{d 1}-T_{d 2}}{R_{r 1}}-\frac{T_{d 1}-T_{c 1}}{R_{\lambda 1}}-\frac{T_{d 1}-T_{a 1}}{R_{\lambda 1}}
\end{array}\right. \\
\left\{\begin{array}{l}
C_{a i} \frac{d T_{a i}}{d t}=Q_{a i}-\frac{T_{a i}-T_{a i-1}}{R_{r i-1}}-\frac{T_{a i}-T_{a i+1}}{R_{r i}}-\frac{T_{a i}-T_{d i}}{R_{\lambda i}}-\frac{T_{a i}-T_{b i}}{R_{\lambda i}} \\
C_{b i} \frac{d T_{b i}}{d t}=Q_{b i}-\frac{T_{b i}-T_{b i-1}}{R_{r i-1}}-\frac{T_{b i}-T_{b i+1}}{R_{r i}}-\frac{T_{b i}-T_{a i}}{R_{\lambda i}}-\frac{T_{b i}-T_{c i}}{R_{\lambda i}} \\
C_{c i} \frac{d T_{c i}}{d t}=Q_{c i}-\frac{T_{c i}-T_{c i-1}}{R_{r i-1}}-\frac{T_{c i}-T_{c i+1}}{R_{r i}}-\frac{T_{c i}-T_{b i}}{R_{\lambda i}}-\frac{T_{c i}-T_{d i}}{R_{\lambda i}} \\
C_{d i} \frac{d T_{d i}}{d t}=Q_{d i}-\frac{T_{d i}-T_{d i-1}}{R_{r i-1}}-\frac{T_{d i}-T_{d i+1}}{R_{r i}}-\frac{T_{d i}-T_{c i}}{R_{\lambda i}}-\frac{T_{d i}-T_{a i}}{R_{\lambda i}} \\
C_{f} \frac{d T_{f}}{d t}=Q_{f}-\frac{T_{f}-T_{a n-1}-\frac{T_{f}-T_{b n-1}}{R_{r n-1}}-\frac{T_{f}-T_{c n-1}}{R_{r n-1}}-\frac{T_{f}-T_{d n-1}}{R_{r n-1}}}{R_{r n-1}}
\end{array}\right.
\end{gathered}
$$

where $i=2,3, \ldots, n-1$, and $T_{a n}=T_{b n}=T_{c n}=T_{d n}=T_{f}$. The equations presented above are rewritten into a matrix form:

$$
\left[\begin{array}{c}
\dot{\boldsymbol{T}}_{1} \\
\vdots \\
\dot{\boldsymbol{T}}_{i} \\
\vdots \\
\dot{\boldsymbol{T}}_{n}
\end{array}\right]=\left[\begin{array}{ccccc}
A_{11} & A_{12} & A_{13} & \cdots & A_{1 n} \\
A_{21} & A_{22} & A_{23} & \cdots & A_{2 n} \\
A_{31} & A_{32} & A_{33} & \cdots & A_{3 n} \\
\vdots & \vdots & \vdots & \ddots & \vdots \\
A_{n 1} & A_{n 2} & A_{n 3} & \cdots & A_{n n}
\end{array}\right]\left[\begin{array}{c}
\boldsymbol{T}_{1} \\
\vdots \\
\boldsymbol{T}_{i} \\
\vdots \\
\boldsymbol{T}_{n}
\end{array}\right]+\left[\begin{array}{c}
\boldsymbol{B}_{1} \boldsymbol{U}_{1} \\
\vdots \\
\boldsymbol{B}_{i} \boldsymbol{U}_{i} \\
\vdots \\
\boldsymbol{B}_{n} \boldsymbol{U}_{n}
\end{array}\right]
$$

In Equation (4), the expressions of all variables are defined as follows:

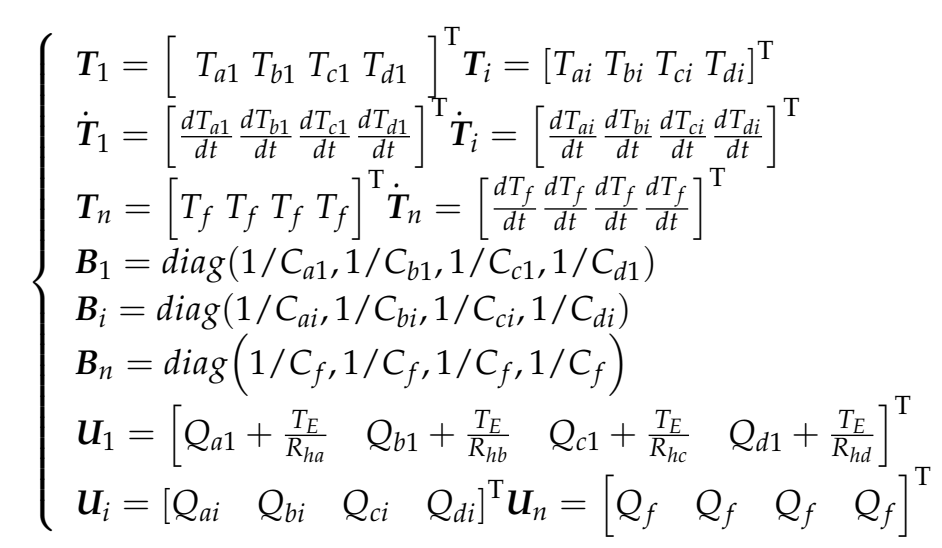

Submatrix $A_{j k}$ in Equation (4) $(j, k=1,2, \ldots, n)$ is a $4 \times 4$ matrix. The values of elements in $A_{j k}$ are expressed in Equation (6), and the specific parameter values are given from Equation (A1)-(A5) in Appendix A.

$$
A_{j k}=\left[\begin{array}{cccc}
A_{j k} & a_{j k} & a_{13} & a_{14} \\
a_{11} & A_{12} & A_{j k} & A_{j k} \\
A_{21} & a_{22} & a_{23} & a_{24} \\
A_{j k} & A_{j k} & A_{j k} & A_{j k} \\
a_{31} & a_{32} & a_{33} & a_{34} \\
A_{j k} & A_{j k} & A_{j k} & A_{j k} \\
a_{41} & a_{42} & a_{43} & a_{44}
\end{array}\right]
$$


The ETN of overhead transmission lines can be established on the basis of the above-mentioned derivation. The equation of state can be expressed as follows:

$$
\dot{T}=A T+B U
$$

where $T$ is the $4 n$-dimension state vector. $\dot{T}$ is the first derivative of $\boldsymbol{T}$. $A$ is a $4 n \times 4 n$ coefficient matrix. $B$ is the $4 n \times 4 n$ input matrix. $U$ is the $4 n$-dimension input column vector. State column vector $T$ reflects the temperature of each node in the ETN of overhead transmission lines. Coefficient matrix $A$ and input matrix $\boldsymbol{B}$ reflect the influence of factors, such as the material, structure of overhead transmission lines, and external meteorological conditions on heat transfer. Input column vector $\boldsymbol{U}$ reflects the influence of line current and radiation on heat transfer. When current of conductor, ambient temperature, wind velocity or radiation intensity changes, the time-domain response of model can be solved to obtain the radial and circumferential temperature distribution and temperature rise response by simply modifying the matrix parameters of the model. The ETN of overhead transmission lines transforms the radial and circumferential temperature calculations into a high-order, multi-input, and multi-output system.

\section{Transient Temperature Calculation Method for Overhead Transmission Line Based on the ETN}

\subsection{Determination of ETN Parameters}

The cross-section of the conductor is divided into $n$ layers through the ETN and is divided into four zones $Z_{a}-Z_{d}$ in the circumferential direction. The parameters of nodes are described by subscripts $x$ and $y(x=a, b, c, d ; y=1,2, \ldots, n-1)$, and the parameters of the central layer are described by subscript $f$. Heat flux $\left(Q_{x y}\right.$ and $\left.Q_{f}\right)$, thermal capacity $\left(C_{x y}\right.$ and $\left.C_{f}\right)$, and thermal resistance $\left(R_{\lambda y}, R_{r y}\right.$, and $R_{h x}$ ) of each node in the ETN can be determined on the basis of the principle of heat transfer.

The cross-section area of the aluminum or steel wire $S_{x y}$ of each node and the cross-section area $S_{f}$ of a central node can be obtained using a geometric division in accordance with the actual conductor specifications.

(1) Heat Flux Parameters

The heat flux of conductor surface $(y=1)$ comprises Joule heat $Q_{J}$, radiant heat $Q_{F}$, and solar heat $Q_{S}$.

$$
Q_{x 1}=Q_{J x 1}-Q_{F x 1}+Q_{S x 1},
$$

where the heat flux of the layers $(y>1)$ only comprises Joule heat:

$$
Q_{x y}=Q_{J x y} ; Q_{f}=Q_{J f} .
$$

According to the definition of resistance, the resistance of each node, the node resistance of the central layer, and the equivalent resistance of the entire conductor are calculated as follows:

$$
\left\{\begin{array}{l}
\Omega_{x y}=\left(\sigma_{x y} L\right) / S_{x y} ; \Omega_{f}=\left(\sigma_{f} L\right) / S_{f} \\
\Omega=\Omega_{a 1} / / \cdots / / \Omega_{x y} / / \cdots / / \Omega_{f}
\end{array},\right.
$$

where $L$ is the length of the conductor. $\sigma_{x y}$ and $\sigma_{f}$ are the node resistivity of the conductor material in the ETN, and the relationship between its value and temperature is expressed as follows:

$$
\sigma(T)=\sigma_{20}[1+\alpha(T-20)],
$$

where $\sigma_{20}$ is the conductor material resistivity at $20^{\circ} \mathrm{C}$, and $\alpha$ is the resistivity temperature coefficient; these variables are related to the commonly used material of conductor [29]. 
According to the definition of Joule heat power, the Joule heat at each node is calculated by the following formula:

$$
Q_{J x y}=\left(I^{2} \Omega^{2}\right) / \Omega_{x y} ; Q_{J f}=\left(I^{2} \Omega^{2}\right) / \Omega_{f},
$$

where $I$ is the current of the conductor.

According to Stefan-Boltzmann law, the radiant heat loss $Q_{F x 1}$ of a conductor surface is related to the temperature difference between the conductor surface and the surrounding environment:

$$
Q_{F x 1}=4.45 L D_{0} \varepsilon\left\{\left[\left(T_{x 1}+237\right) / 100\right]^{4}-\left[\left(T_{E}+237\right) / 100\right]^{4}\right\},
$$

where $D_{0}$ is the conductor's outer diameter, and conductor emissivity $\varepsilon$ ranges from 0.23 to 0.91 [29].

For conductor solar heat $Q_{S x 1}$ :

$$
Q_{S x 1}=\left(\delta A^{\prime} L Q_{s e} \sin \theta_{x}\right) / 4,
$$

where $\delta$ is the solar absorption rate, $Q_{s e}$ is the corrected radiation power of per unit area above sea level, $\theta_{x}$ is the effective incident angle of sunlight in $Z_{a}-Z_{d}$, and $A^{\prime}$ is the illumination area per unit length. The values of the above-mentioned parameters can be found in [17].

(2) Equivalent Thermal Capacity Parameters In accordance with the definition of thermal capacity, thermal capacity parameters $C_{x y}$ and $C_{f}$ are expressed as:

$$
C_{x y}=L \rho_{x y} S_{x y} C_{x y} ; C_{f}=L \rho_{f} S_{f} \mathcal{C}_{f},
$$

where $\rho_{x y}, \rho_{f}, c_{x y}$, and $c_{f}$ are the density and thermal capacity of conductor material contained in the nodes of the ETN [29].

(3) Equivalent Thermal Resistance Parameters The circumferential and radial thermal resistances can be calculated by the principle of heat transfer:

$$
R_{\lambda y}=\frac{\pi\left(r_{y}+r_{y+1}\right)}{4 K_{\lambda} L\left(r_{y}-r_{y+1}\right)}, R_{r y}=\frac{1}{\pi K_{r} L}\left[\frac{2 r_{y}^{2} \ln \left(r_{y} / r_{y+1}\right)}{r_{y}^{2}-r_{y+1}^{2}}-1\right],
$$

where $r_{y}$ is the radius of the $y$ th layer of the conductor, and $K_{\lambda}$ and $K_{r}$ correspond to the equivalent thermal conductivity along the circumferential and radial directions of the conductor; these variables are related to the conductor material [30].

(4) Equivalent Thermal Convection Parameters Thermal convection resistance $R_{h x}$ are expressed as:

$$
R_{h x}=4 /\left(\pi D_{0} L h_{x}\right),
$$

where $h_{x}$ is the convective heat transfer coefficient of $Z_{a}-Z_{d}$. The change in $h_{x}$ becomes complicated when laminar flow sweeps across the conductor; these variables can be calculated by using the following equation:

$$
\left\{\begin{array}{l}
h_{x}=\frac{f_{x} \cdot\left(N u_{f}\right)_{x}+p_{x} \cdot\left(N u_{p}\right)_{x} \cdot k_{a i r}}{D_{0}} ;\left(N u_{f}\right)_{x}=a\left(G r_{x} P r\right)^{b} ;\left(N u_{p}\right)_{x}=A_{P}\left(R_{e}\right)^{n}(P r)^{1 / 3} \\
G r_{x}=\frac{g\left(T_{x 1}-T_{E}\right) D^{3}}{v_{0}^{2}\left(273+\left(T_{x 1}+T_{E}\right) / 2\right)} ; \operatorname{Pr}=\mu / k ; R_{e}=D_{0} v \rho_{a} / \mu
\end{array},\right.
$$

where $N u_{f}$ and $N u_{p}$ are the Nusselt numbers of natural and forced convective heat transfers, respectively. $N u_{f}$ and $N u_{p}$ are different when the fluid sweeps across various parts of the conductor surface and must be corrected by $f_{x}$ and $p_{x}$. Gr $r_{x}$ is the Grashof number of different parts of the conductor, $g$ is the 
acceleration of gravity, $k_{a i r}$ is the air thermal conductivity, $v_{0}$ is the kinematic viscosity, $\rho_{a}$ is the air density, $R e$ is the Reynolds number, $\mu$ is the air viscous coefficient, and $v$ is the wind speed. Under air cooling conditions, $a$ and $b$ are constants determined by wind direction $\varphi . A_{p}$ and $n$ are constants determined by the Reynolds number and can be obtained from [31].

\subsection{Transient Temperature Calculation Method with Nonlinear Iteration}

On the basis of the derivation of the above-mentioned parameters in the ETN, the following factors must be considered in solving transient temperature: (a) convective thermal resistance and radiant heat are the functions of temperature difference between fluid and solid interfaces; (b) conductor resistivity is related to temperature, and Joule heat is the function of temperature. Therefore, nonlinear iteration is adopted to solve the time domain response of the ETN. The concrete steps are exhibited in Figure 4.

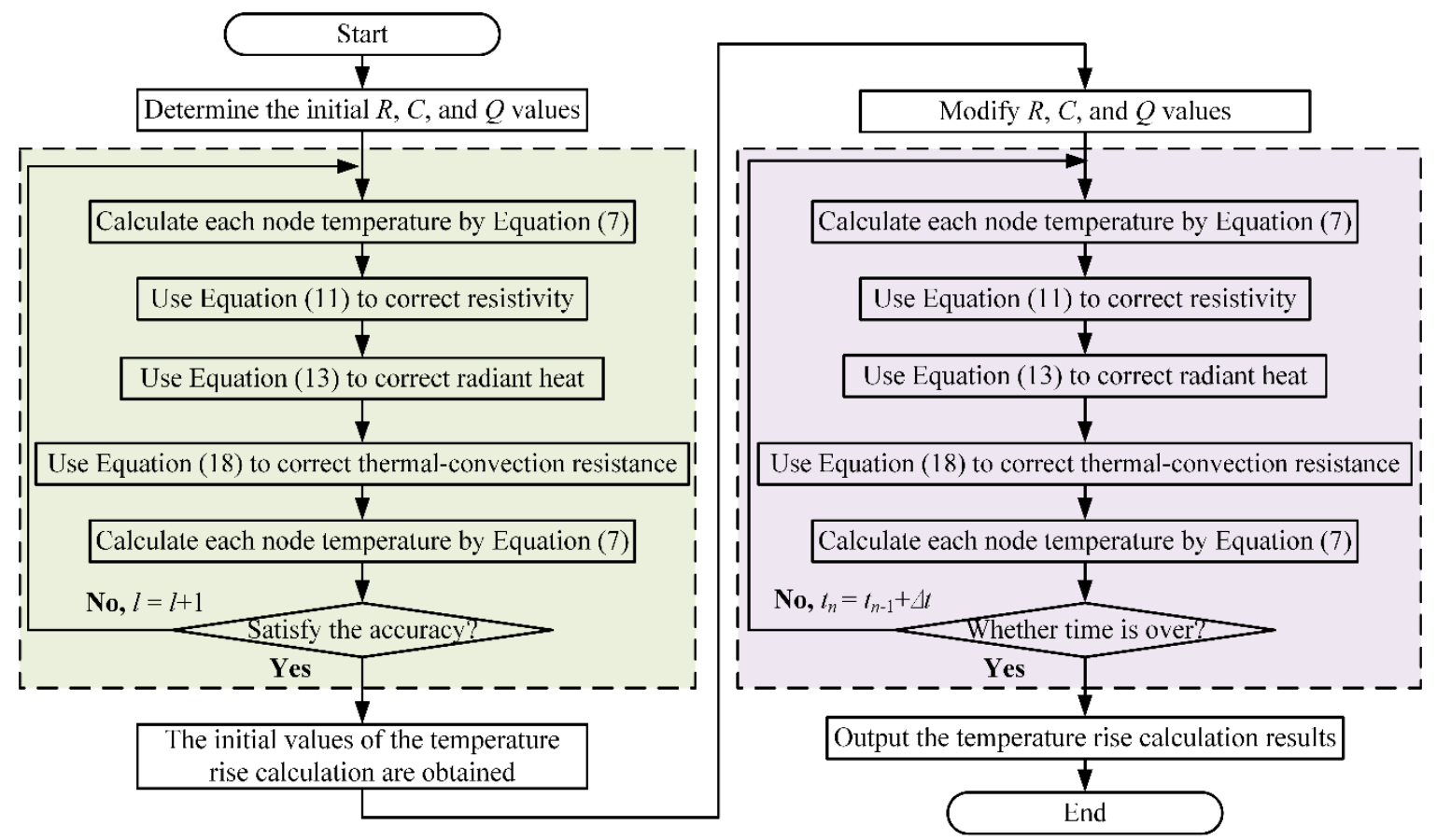

Figure 4. Transient temperature calculation method of overhead transmission line with nonlinear iteration.

The transient temperature calculation of ETN involves two stages of iterations, namely, convergence iteration and marching-on-in-time algorithm. The specific steps are presented as follows:

Step 1: Acquire conductor parameters, meteorological parameters, and current, and determine the initial values of $Q, C$, and $R$ of the ETN by Equations (8)-(18). The initial temperature of each node is ambient temperature $T_{E}$.

Step 2: Calculate temperature of each node by Equation (7), and modify resistivity, radiant heat of nodes, and thermal convection resistance by Equations (11), (13) and (18), correspondingly. Thus, the temperature values of each node of the ETN can be solved.

Step 3: Assess whether the temperature difference between two adjacent iterations satisfies the control precision (considered $0.01{ }^{\circ} \mathrm{C}$ in this paper). Otherwise, set the number of iterations $l$ to $l+1$, and continue the calculation until the temperature difference is less than that of the given precision.

Step 4: Adjust the Joule heat of nodes of the ETN by current. Use the temperature value outputted in Step 3 as the initial value of the transient temperature rise response calculation for subsequent iterations. 
Step 5: Determine whether the calculation is completed. Otherwise, set time $t_{n}=t_{n-1}+\Delta t$ for the calculation until the calculation time is equal to the prescribed time.

Step 6: Obtain the calculation results of the transient temperature rise response, and the calculation is completed.

\section{Experimental Verification of the Model and Calculation Method}

\subsection{Temperature Rise Test Platform of Overhead Transmission Lines}

A test platform of conductor temperature rise is designed to verify the effectiveness of the proposed model and calculation method, as displayed in Figure 5a,b. The test platform mainly consists of a triangular column steel frame, large current generator, controllable blower, current transformer, temperature sensor, ultrasonic anemometer, radiation intensity measuring instrument, and multi-channel data acquisition device. The main parameters of experimental equipment are shown in Table A1 of the Appendix B.

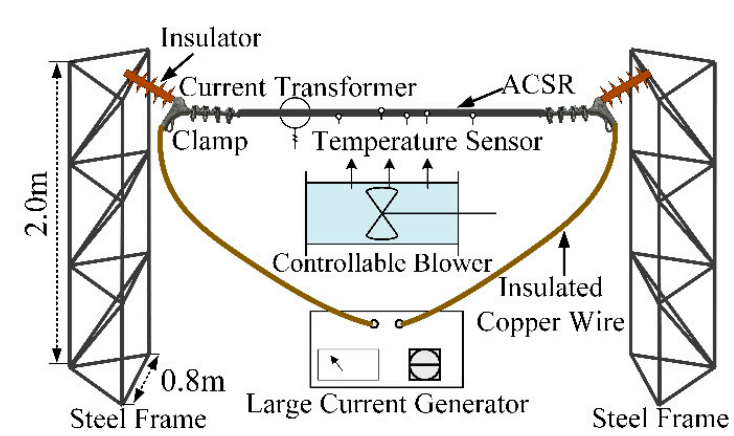

(a)

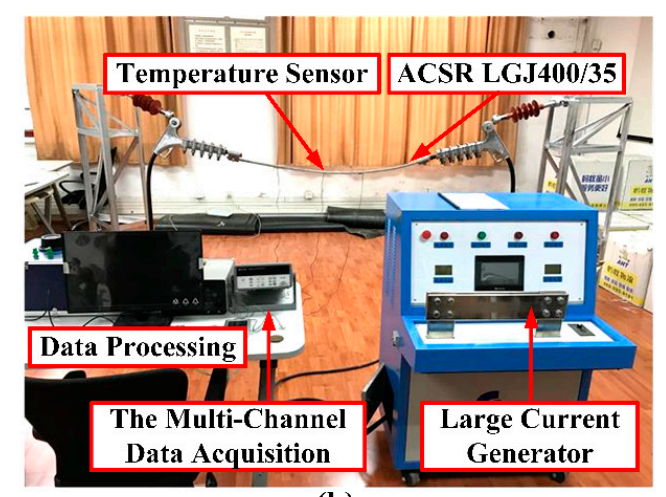

(b)

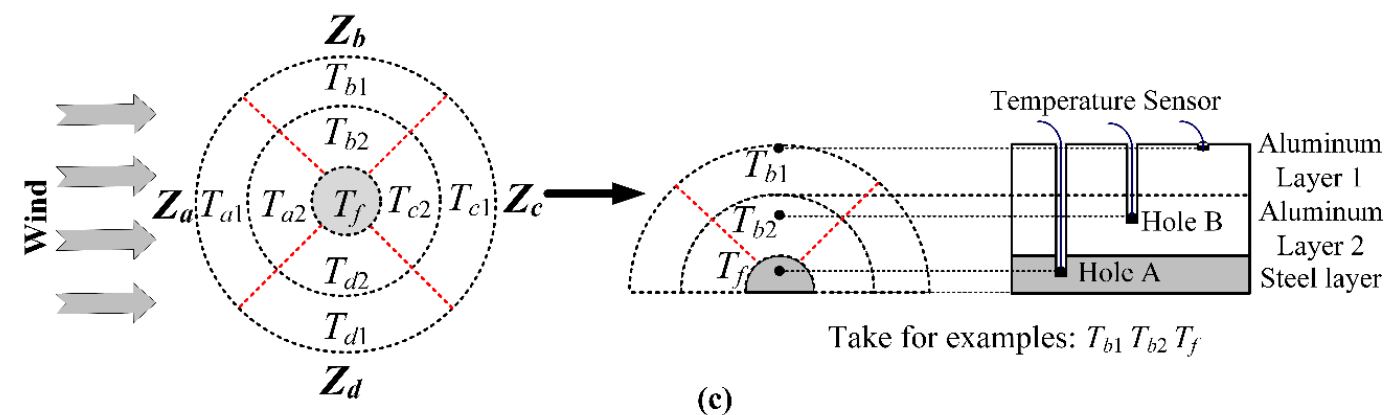

Figure 5. Test platform of overhead transmission line temperature measurement. (a) Platform schematic; (b) Platform photo; (c) Diagram of temperature measuring point position.

The conductor type in the test is ACSR LGJ400/35, and the parameters are listed in Table A2 of the Appendix B. The emissivity $\varepsilon$ and solar absorptivity $\delta$ of the conductor increase with age from about $0.2-0.5$ when new to about $0.8-0.9$ within several years [17]. The conductor used in this test is not a new one. Hence, the values of $\varepsilon$ and $\delta$ are both 0.9 in this test platform.

The tested conductor is divided into three layers $(n=3)$, and temperature monitoring probes are installed in the conductor surface, aluminum layer, and steel layer in $Z_{a}-Z_{d}$, as is shown in Figure 5c. Taking $T_{b 1}, T_{b 2}$, and $T_{f}$ for examples, three temperature measuring points $\left(T_{f}\right.$ in hole-A, $T_{b 2}$ in hole-B, $T_{b 1}$ on the surface) are placed at equal intervals along the axial direction. The internal temperature sensors are attached by drilling a small hole (its diameter is smaller than $1.2 \mathrm{~mm}$ ) through the aluminum and steel layers. The temperatures of the conductor are collected by platinum film resistance temperature probes (PT1000) and uploaded to PC computer via the multi-channel data acquisition unit with the sample frequency of $50 \mathrm{~Hz}$. 
In Table 1, the experimental groups are evaluated under the influence of forced convection and current. The step current is from $0 \mathrm{~A}$ to $300 \mathrm{~A}$ or $900 \mathrm{~A}$, and the average wind velocity is from $0 \mathrm{~m} / \mathrm{s}$ to $3 \mathrm{~m} / \mathrm{s}$ (range of difference must not exceed $\pm 0.1 \mathrm{~m} / \mathrm{s}$ ). A total of 49 sets of tests are evaluated. The ambient temperature is $25{ }^{\circ} \mathrm{C}\left( \pm 0.1{ }^{\circ} \mathrm{C}\right)$, humidity is $40 \%( \pm 0.1 \%)$, and radiation intensity is $400 \mathrm{~W} / \mathrm{m}^{2}\left( \pm 5 \mathrm{~W} / \mathrm{m}^{2}\right)$. These parameter values are constants during the tests.

Table 1. Test group parameters $(7 \times 7=49$ groups $)$.

\begin{tabular}{cc}
\hline Current (A) & Wind Speed $(\mathbf{m} / \mathbf{s})$ \\
\hline 300 & 0 \\
400 & 0.5 \\
500 & 1.0 \\
600 & 1.5 \\
700 & 2.0 \\
800 & 2.5 \\
900 & 3.0 \\
\hline
\end{tabular}

Figure 6 presents the temperature distribution and the difference of temperature rise response of the conductor under experimental conditions.

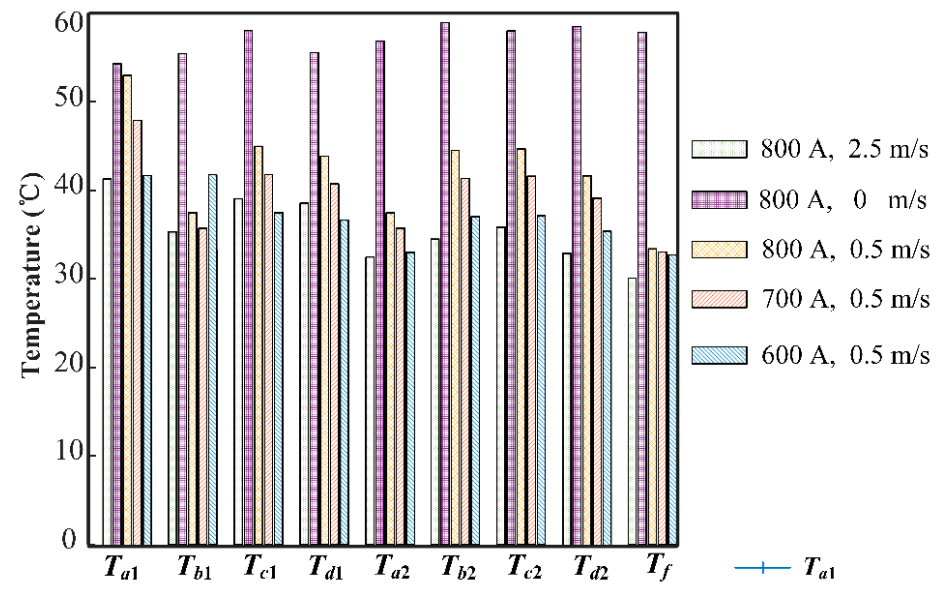

(a)

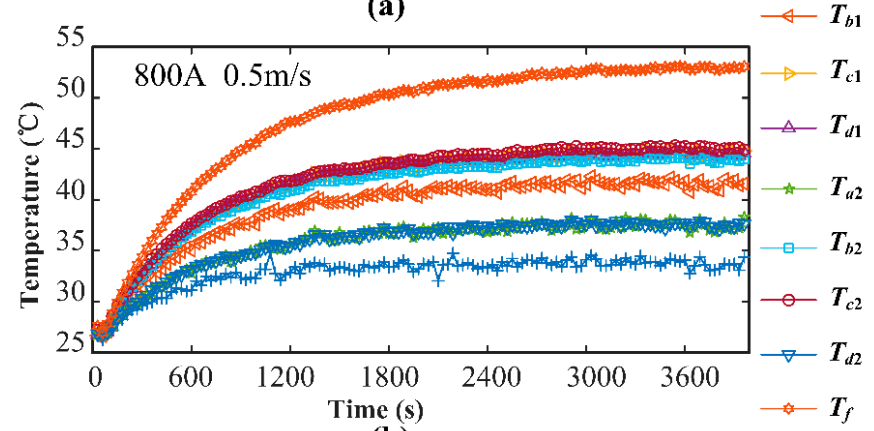

(b)

Figure 6. Temperature result of overhead transmission lines in the test case. (a) Radial circumferential steady-state temperature gradient distribution; (b) Difference in radial circumferential temperature rise response.

In Figure 6a, the radial and circumferential gradient distributions of temperature inside the conductor and the temperature differences increase with current. The temperature difference between the windward zone and steel layer reaches $9.8^{\circ} \mathrm{C}$ when the current is $600 \mathrm{~A}$ and it reaches $14.9^{\circ} \mathrm{C}$ when the current is $700 \mathrm{~A}$. Although the temperature of each point presents a downward trend in general, the temperature difference between different zones shows a non-monotonic change with the increase 
in forced convection intensity. Under natural convection (i.e., $0 \mathrm{~m} / \mathrm{s}$ ), the maximum temperature difference between the conductor surface and steel core is only $5.3^{\circ} \mathrm{C}$. The maximum temperature difference is $21.7^{\circ} \mathrm{C}$ when the wind velocity is $0.5 \mathrm{~m} / \mathrm{s}$. However, the maximum temperature difference is $13.4{ }^{\circ} \mathrm{C}$ when the wind velocity is $2.5 \mathrm{~m} / \mathrm{s}$. In Figure $6 \mathrm{~b}$, the heating rate of the conductor steel core is the largest, whereas the heating rate at the windward zone of the conductor surface is the smallest. The heating rate is constantly smaller in the outer layer than in the inner layer.

The test of temperature rise response verifies that radial heat transfers occurs inside and outside the conductor in forced convection. Circumferential heat transfers of the conductor occurs due to different intensities of forced convection. Neglect of circumferential heat transfer paths in model establishment will inevitably cause the calculation errors.

\subsection{Verification of the Model and Calculation Method}

To confirm the effectiveness of the model, the test results of conductor temperature rise response $T(t)^{\text {test }}$ are compared with the calculation results of model $T(t)^{\text {calc }}$ under the condition where the current is $900 \mathrm{~A}$, and the wind velocity is $0.5 \mathrm{~m} / \mathrm{s}$.

Figure 7a illustrates the comparison of temperature results obtained by the calculation method and test. The calculated curves are basically consistent with the test curves. Furthermore, in order to make quantitative analysis on the difference between tested and calculated, absolute relative error $\delta_{e}$ and average absolute relative error $\delta_{\text {avg }}$ are defined in Equation (19), where $m$ is the total number of samples:

$$
\delta_{e}=\left|\frac{T(t)^{\text {test }}-T(t)^{\text {calc }}}{T(t)^{t e s t}}\right| \times 100 \%, \delta_{\text {avg }}=\frac{1}{m} \sum_{i=1}^{m} \delta_{e}
$$

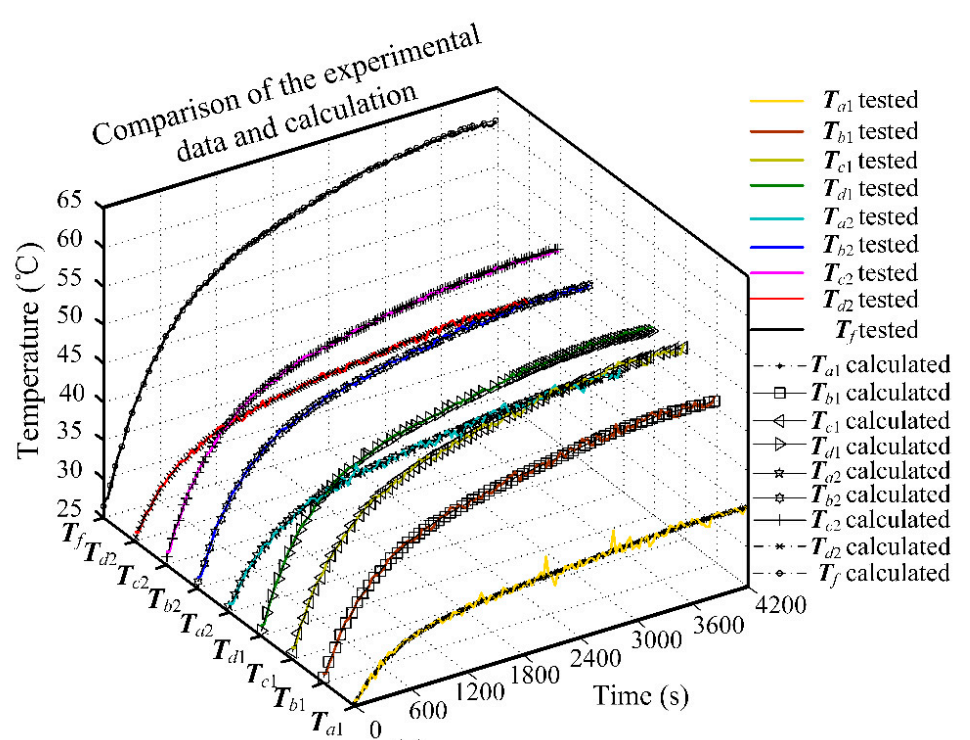

(a)

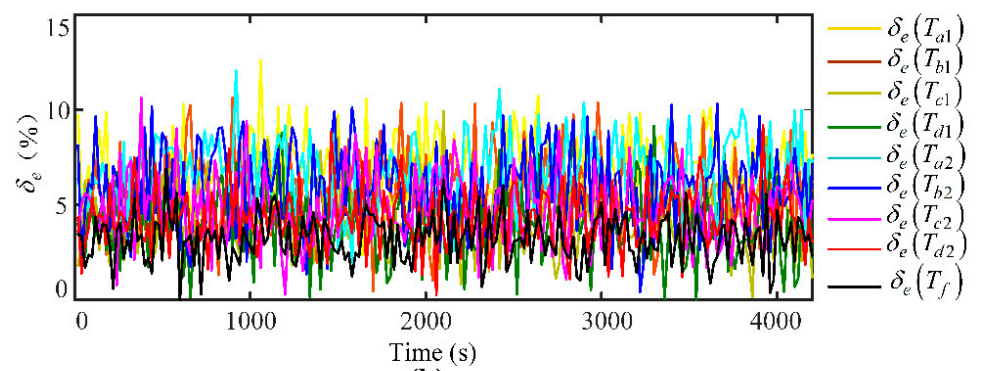

(b)

Figure 7. Cont. 


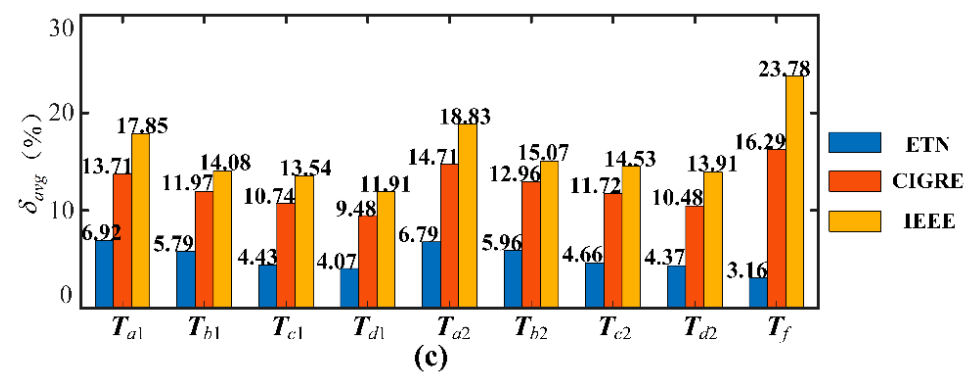

Figure 7. Verification of temperature calculation methods based on ETN. (a) Comparison of temperature rise test and calculation results; (b) Absolute relative error $\delta_{e}$ in different zones of the conductor cross-section; (c) Comparison of average absolute relative error $\delta_{\text {avg }}$ between non-linear iterations and standard calculations.

As depicted in Figure $7 \mathrm{~b}$, absolute relative error $\delta_{e}$ of nonlinear iteration nearly ranges from $5 \%$ to $10 \%$, and the maximum $\delta_{e}$ is less than $13 \%$. This indicates that the ETN has a huge calculation precision and can preferably reflect the transient temperature changes in overhead transmission line cross-section.

In the same experimental condition, the calculated results of the ETN are compared by adopting the IEEE and CIGRE standards $[17,18]$. The average absolute relative error $\delta_{\text {avg }}$ of the conductor steel core and aluminum layer are plotted in Figure 7c.

Both the IEEE and CIGRE standards take account of the temperature-dependent resistance. But the CIGRE is more detailed in the selection of other model parameters, the accuracy of IEEE is little lower than that of CIGRE. The IEEE and CIGRE standards simplify the conductor to concentric cylinders and treat it as an isothermal component, which ignores the influence of radial and circumferential heat transfer paths and only can calculate the single point temperature of conductor (surface or average temperature).

Therefore, comparing with the ENT model, the $\delta_{\text {avg }}$ of the calculated results of the IEEE and CIGRE standards are relatively higher. The maximum $\delta_{\text {avg }}$ in the conductor steel core can reach $23.78 \%$ and $16.29 \%$, respectively. The proposed ENT model not only can consider the influence of temperature-dependent parameters (material properties, convective heat resistances, and radiation heat fluxes) in the calculation of transient temperature rise, but also can reflect the transient temperature distribution of different parts of the conductor cross-section. Thus, the ENT with nonlinear iteration method has a relatively higher accuracy. The $\delta_{\text {avg }}$ of the calculated results of the ENT are below $7 \%$.

\subsection{Extrapolation and Validation}

In order to verify the adaptability of model, more confirmatory tests are added by changing the current, ambient temperature, and wind velocity. In Table 2, 27 groups of tests are conducted to obtain 243 groups of temperature rise test data of nodes under different conditions. Make a comparison between calculation method of the ETN and test data, and the average absolute relative error $\delta_{\text {avg }}$ of each node is obtained.

Table 2. Parameters of the additional extrapolation verification tests ( $3 \times 3 \times 3=27$ groups).

\begin{tabular}{ccc}
\hline Current (A) & Air Temperature $\left({ }^{\circ} \mathbf{C}\right)$ & Wind Speed $(\mathbf{m} / \mathbf{s})$ \\
\hline 1000 & 15 & 0.5 \\
1100 & 20 & 2.0 \\
1200 & 35 & 3.0 \\
\hline
\end{tabular}

The frequency distribution histograms of 243 groups are fitted by the normal distribution, and the curves are plotted in Figure 8. The $\delta_{\text {avg }}$ of the ETN is subjected to $N(4.92,1.86)$. According to the definition of normal distribution, the maximum $\delta_{\text {avg }}$ of the ETN is $7.59 \%$ when the confidence interval is 
$95 \%$, thereby satisfying the calculation requirements of temperature distribution and temperature rise response of overhead transmission lines. The $\delta_{\text {avg }}$ of CIGRE is subjected to $N(12.88,6.46)$. The $\delta_{\text {avg }}$ of IEEE is subjected to $N(15.87,13.86)$. The computational accuracy of the standards is all lower than the ETN.

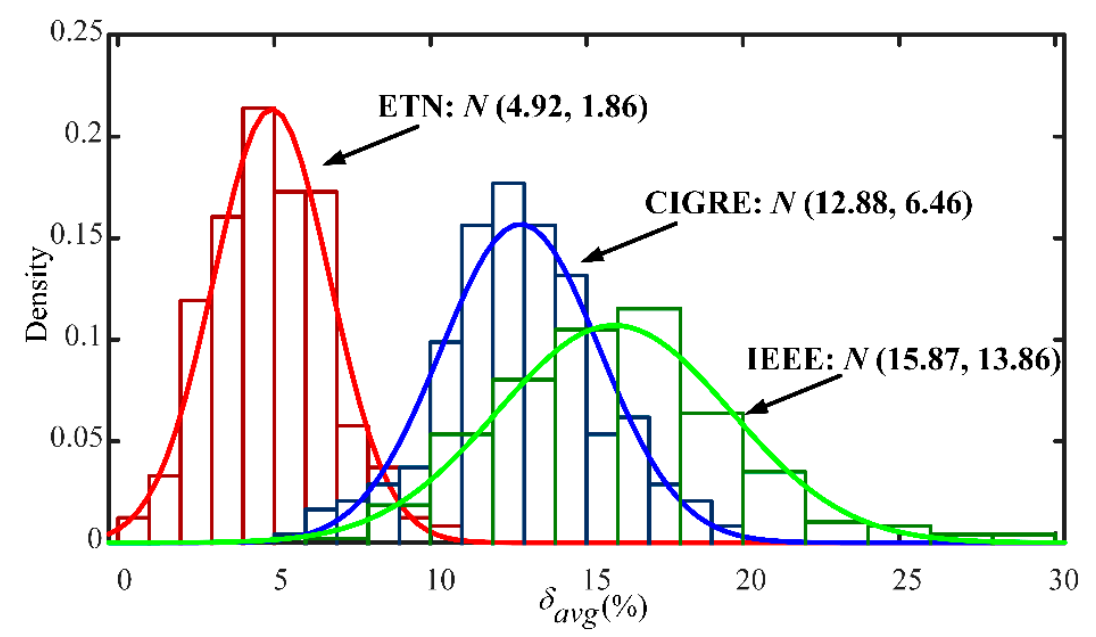

Figure 8. Frequency distribution histogram of the average absolute relative error $\delta_{\text {avg }}$ of the methods under the verification test conditions.

Therefore, the ETN with radial and circumferential temperature distributions and the nonlinear iteration can improve the accuracy of the temperature simulation of overhead transmission lines. The temperature test provides sufficient evidence to validate the effectiveness and precision of the proposed model.

\section{MPTP Based on the Transient Temperature of Overhead Transmission Lines}

\subsection{Transient Temperature Estimation of the Entire Overhead Transmission Lines}

The transient temperature rise of each layer of conductor cross-section can be accurately calculated by the abovementioned ETN. The transmission lines in the actual operation frequently span a very long area. The diversity of meteorological conditions around the transmission lines must be completely considered in calculating the transient temperature rise response. Therefore, the entire line can be divided into $N$ segments in accordance with the geographical environment and surrounding meteorological distribution characteristics of transmission lines. Real-time meteorological parameters in each segment can be obtained by refined numerical weather forecast technology and on-line monitoring devices of transmission lines [32-35].

As depicted in Figure 9a, a transmission line is divided into $N$ segments according to the number of strain sections, and each strain section corresponds to an equivalent meteorological region. Real-time meteorological parameters can be acquired by all kinds of on-line monitoring devices, such as micrometeorological stations located along transmission corridor, monitoring stations on tower and monitoring devices installed on the transmission line:

$$
x(i)=\left[T_{E}(i), \quad S_{E}(i), \quad v(i), \quad \varphi(i)\right]
$$

In Equation (20), real-time equivalent meteorological parameters $x(i)$ of each segment of line can be determined. The main meteorological parameters related to temperature rise response containing ambient temperature $T_{E}(i)$, solar radiation $S_{E}(i)$, wind velocity $v(i)$, and wind direction $\varphi(i)$ can be obtained by on-line monitoring devices including environment temperature thermistor sensor, total-radiation solar radiation sensor, ultrasonic anemometer and micrometeorological stations. 
Particularly, the wind velocity $v_{c}(i)$ measured by micrometeorological stations should be converted to obtain equivalent real-time wind velocity $v(i)$ of corresponding tower height by Equation (21) since micrometeorological stations are not at the same height as transmission line. However, the conversion is unnecessary for the wind velocity measured by monitoring stations on tower and monitoring devices installed on the transmission line:

$$
v(i)=v_{c}(i) \cdot \beta\left(\frac{H}{h_{c}}\right)^{Z_{0}},
$$

where $H$ is the average height above ground of each segment of line, $h_{c}$ is the height above ground of micrometeorological stations, $Z_{0}$ and $\beta$ are wind shear exponent and correction factor respectively and both are influenced by surface roughness. The values of $Z_{0}$ and $\beta$ are available in the [36].

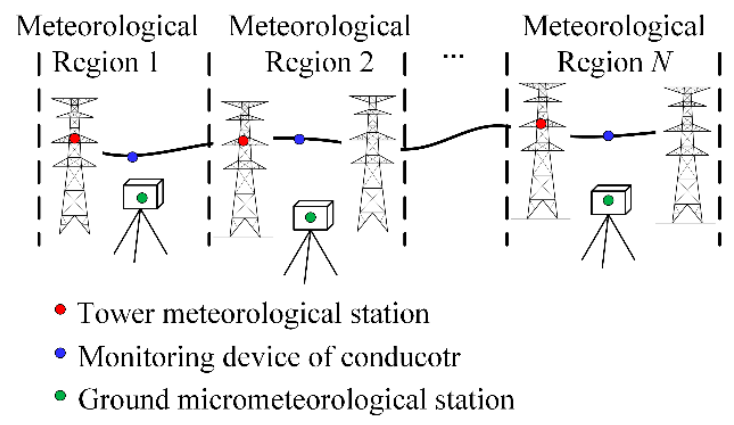

(a)

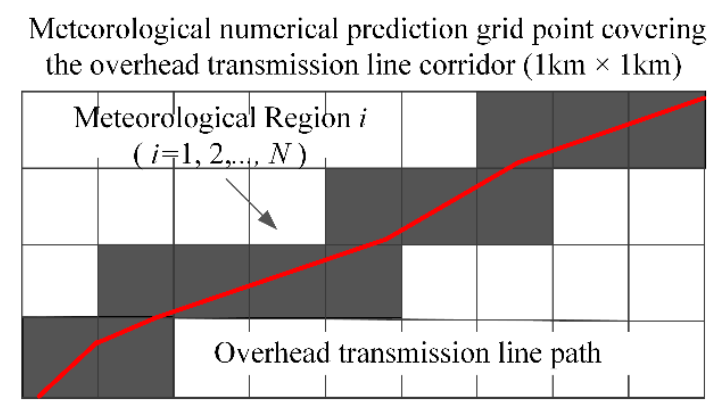

(b)

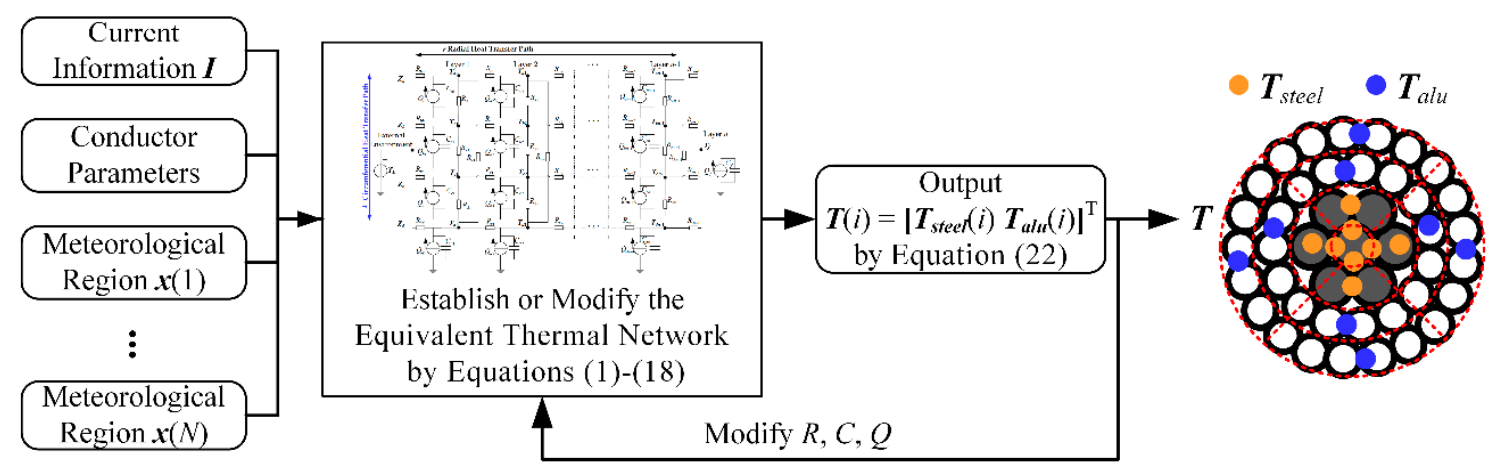

(c)

Figure 9. Transient temperature estimation of overhead transmission lines. (a) Acquisition of real-time meteorological parameters of each segment by on-line monitoring devices; (b) Acquisition of real-time meteorological parameters of each segment by refined numerical weather forecast; (c) Real-time feedback calculation and modification based on the ETN.

For the case where there are no monitoring devices along transmission line, meteorological division can be realized according to grid partition of modern refined numerical weather forecast technology, as described in Figure $9 \mathrm{~b}$. Based on the combination of the location of transmission line and grid of refined weather forecast (e.g., $1 \mathrm{~km} \times 1 \mathrm{~km}$ ), long-distance transmission line is divided corresponding to $N$ grids and equivalent meteorological parameters in each divided grid can be obtained from weather forecast. The equivalent real-time meteorological parameters also should be converted by Equation (21), and $h_{c}$ in Equation (21) is substituted with the height of automatic meteorological stations. Moreover, combining historical meteorological data and long-term meteorological statistic data from the same geographic location with weather forecast technology, the real-time meteorological parameters of each segment of line can be modified by intelligence algorithms to improve the accuracy of $x(i)$.

On the basis of acquired real-time meteorological parameters $x(i)$ of $i$ segment of line in different regions, the transient temperature of conductor $\boldsymbol{T}(i)=\left[\boldsymbol{T}_{\text {steel }}(i) \boldsymbol{T}_{\text {alu }}(i)\right]^{\mathrm{T}}$ of the $i$ cross-section can be 
calculated by the proposed ETN model with feedback correction. Finally, comprehensive consideration of calculated results of transient temperature of multiple segment of line provides estimation of temperature rise response of the entire transmission line $T=\left[\boldsymbol{T}_{\text {steel }} \boldsymbol{T}_{\text {alu }}\right]^{\mathrm{T}}$. The flowchart of calculation is plotted in Figure 9c:

$$
\left\{\begin{array}{l}
\boldsymbol{T}(i)=f(I, x(i), t)=\left[\begin{array}{ll}
\boldsymbol{T}_{\text {steel }}(i) & \boldsymbol{T}_{\text {alu }}(i)
\end{array}\right]^{\mathrm{T}} \quad i=1,2, \cdots, N \\
\boldsymbol{T}_{\text {steel }}=\left[\begin{array}{l}
\boldsymbol{T}_{\text {steel }}(1), \cdots, \boldsymbol{T}_{\text {steel }}(i), \cdots, \boldsymbol{T}_{\text {steel }}(N) \\
{ }^{\mathrm{T}}
\end{array}\right. \\
\boldsymbol{T}_{\text {alu }}=\left[\begin{array}{ll}
\boldsymbol{T}_{\text {alu }}(1), \cdots, \boldsymbol{T}_{\text {alu }}(i), \cdots, \boldsymbol{T}_{\text {alu }}(N)
\end{array}\right]^{\mathrm{T}} \\
\boldsymbol{T}=\left[\begin{array}{ll}
\boldsymbol{T}_{\text {steel }} & \boldsymbol{T}_{\text {alu }}
\end{array}\right]^{\mathrm{T}}
\end{array},\right.
$$

where $T$ is the transient temperature vector of the entire line, which is a $4 N n \times 1$ time-varying matrix. $T_{\text {steel }}$ and $T_{\text {alu }}$ represent the transient temperature vectors of the steel core and aluminum layer, correspondingly. These vectors are $4 n_{s} N \times 1$ and $4 n_{a} N \times 1$ time-varying matrices, respectively $(n$ is the number of layers of the conductor cross-section in the ETN. $n_{s}$ is the number of steel core layers, and $n_{a}$ is the number of aluminum layers, $n=n_{s}+n_{a}$ ). The function $f$ describes the calculation process of the ETN:

$$
\left\{\begin{array}{l}
T_{\text {steel }(\max )}=\left\|\boldsymbol{T}_{\text {steel }}\right\|_{\infty}, T_{\text {alu }(\max )}=\left\|\boldsymbol{T}_{\text {alu }}\right\|_{\infty} \\
T_{\text {line }}=\max \left\{T_{\text {steel }(\max )}, T_{\text {alu }(\max )}\right\}
\end{array}\right.
$$

The maximum transient temperatures $T_{\text {steel }(\max )}$ and $T_{a l u(\max )}$ can be obtained by solving the infinite norms of $\boldsymbol{T}_{\text {steel }}$ and $\boldsymbol{T}_{\text {alu }}$, and the maximum value between $T_{\text {steel(max) }}$ and $T_{\text {alu(max) }}$ can be used to characterize the transient temperature of the entire line $T_{\text {line }}$.

\subsection{MPTP Strategy of Overhead Transmission Lines}

Regarding the safe operation of the transmission line, the maximum allowable value of the operating temperature of the conductor is usually set. The maximum allowable temperature is determined by many safety constraints, such as mechanical strength loss, stressing, and sagging. For rated or normal current-carrying lines, $T_{N}$ represents the long-term allowable temperature. For overload lines, a higher temperature value $T_{M}$ is set as the short-term allowable temperature of the conductor. However, the temperature of the transmission line causes permanent damage to its mechanical strength when it exceeds the limit temperature $T_{L}$ of the conductor, which requires a timely removal of the line. The values of $T_{N}, T_{M}$, and $T_{L}$ depend on many factors, such as types and operating conditions of the conductor. For ASCR, $T_{N}$ is typically set to $70{ }^{\circ} \mathrm{C}, T_{M}=100{ }^{\circ} \mathrm{C}$, and $T_{L}=120{ }^{\circ} \mathrm{C}$ [37].

Therefore, $T_{N}-T_{M}-T_{L}$ set the "safe range" for the temperature rise of the conductor. The MPTP logic of the line is designed on the basis of the transient temperature calculation trajectory of overhead transmission lines in Equations (22)-(23), as exhibited in Figure 10.

When $T_{\text {line }}$ exceeds the alarm temperature $T_{N}$, it shows that transmission line is in a state of alarm condition but safe, and an alarm signal is sent to the dispatching system. When $T_{\text {line }}$ exceeds the emergency temperature $T_{M}$, taking short-term heat accumulation effect in transient temperature rise process into account, the temperature-time integral $W_{\text {line }}$ during overloading is calculated by Equation (24). The line is tripped off by protection when Equation (25) is satisfied and the real-time calculated integral is greater than that of $W_{\text {set }}$, which is the setting value of the thermal integral. The line is immediately cut off by protection when $T_{\text {line }}$ exceeds the limit temperature $T_{L}$ :

$$
\begin{gathered}
W_{\text {line }}=\int\left(T_{\text {line }}-T_{M}\right) d t, T_{\text {line }}>T_{M} \\
W_{\text {line }}>W_{\text {set }}
\end{gathered}
$$



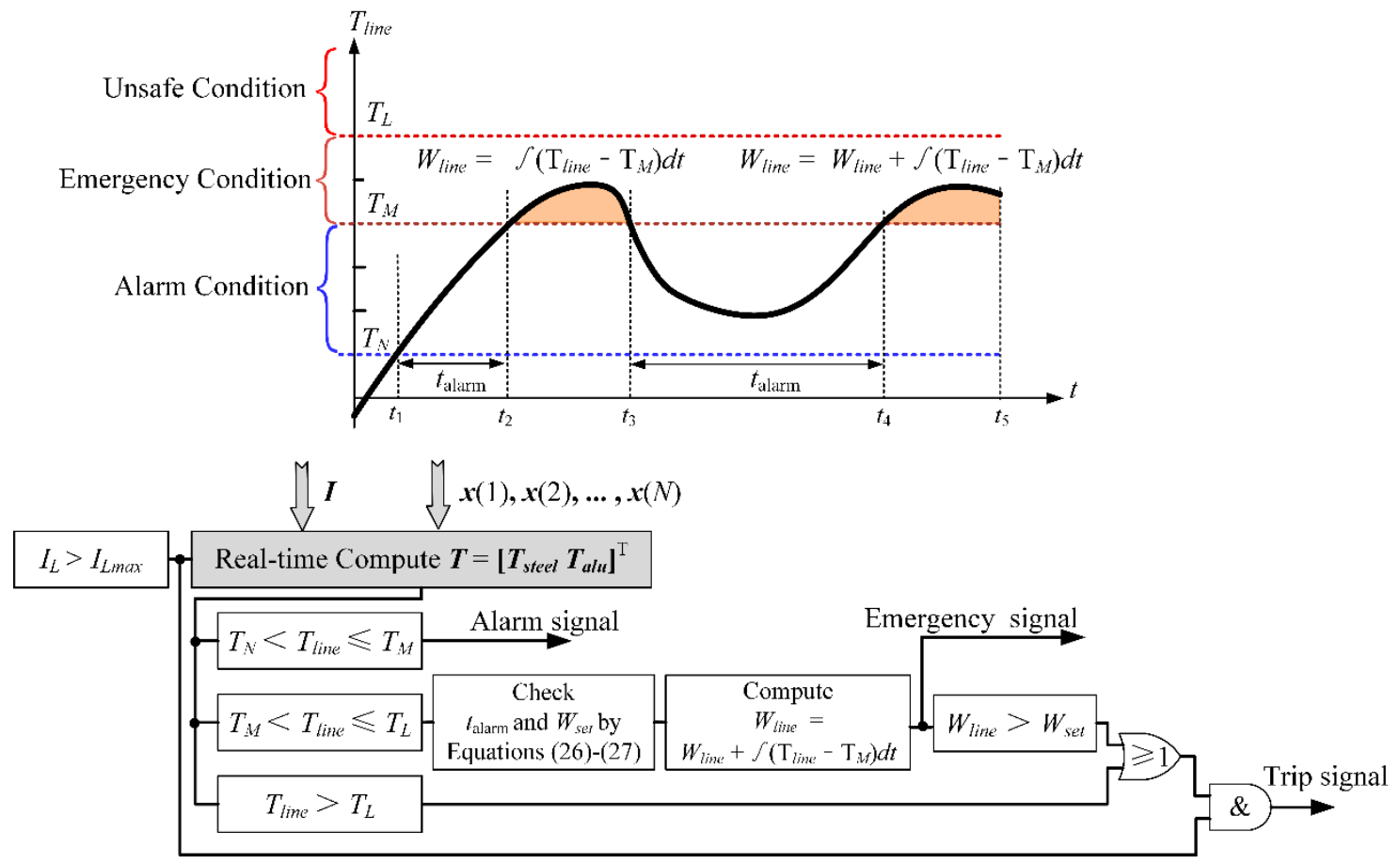

Figure 10. Logic block diagram of the MPTP based on transient temperature of overhead transmission lines.

The temperature of transmission lines may fluctuate in a range of emergency temperature $T_{M}$ given the change in ambient meteorological condition and power flow of the power system, as displayed in Figure 10. The transient temperature changes are expressed in $t_{2}-t_{3}-t_{4}-t_{5}$. Considering the heat accumulation effect, time $t_{\text {alarm }}$ is recorded when the transient temperature of a transmission line is under an alarm condition. The previous temperature-time integral $W_{\text {line }}$ cannot be ignored when $t_{\text {alarm }}$ is small (for example, $t_{\text {alarm }}<10 \mathrm{~min}$ ). Therefore, the previous calculation value must be stored when the line temperature reduces below $T_{M}$. When line temperature is higher than $T_{M}$ again, the temperature-time integral must be calculated on the basis of the previous integral value. However, when $t_{\text {alarm }}$ is large (for example, $t_{\text {alarm }}>10 \mathrm{~min}$ ), the previous integral value should be set to 0 for a new integral calculation. The mathematical expression is displayed in Equation (26):

$$
W_{\text {line }}=\left\{\begin{array}{l}
0, \quad t_{\text {alarm }}>10 \mathrm{~min} \\
W_{\text {line, }} \quad t_{\text {alarm }} \leq 10 \mathrm{~min}
\end{array}\right.
$$

The steel core inside the conductor bears stress and it is the critical factor that affects the sagging security of the line. Temperature differences are observed between the steel core and aluminum layer of a conductor cross-section. The standards require that the maximum allowable operating temperature of the conductor must be reduced to guarantee security when the temperature difference between the steel core and aluminum layer is greater than $10{ }^{\circ} \mathrm{C}$. Consequently, the setting value of $W_{\text {set }}$ must be adjusted on the basis of the difference between $T_{\text {steel }(\max )}$ and $T_{a l u(\max )}$, as expressed in Equation (27). The common ASCR is allowed to run dozens of minutes under $100^{\circ} \mathrm{C}-120^{\circ} \mathrm{C}$ [38]; thus, $W_{\mathrm{I}}$ and $W_{\mathrm{II}}$ can be set to $6000^{\circ} \mathrm{C} \cdot \mathrm{s}$ and $5000{ }^{\circ} \mathrm{C} \cdot \mathrm{s}$ in this protection strategy:

$$
W_{\text {set }}= \begin{cases}W_{I}, & \left|T_{\text {steel (max) }}-T_{\text {alu(max })}\right| \leq 10^{\circ} \mathrm{C} \\ W_{\text {II }}, & \left|T_{\text {steel }(\text { max })}-T_{\text {alu(max })}\right|>10^{\circ} \mathrm{C}\end{cases}
$$


The MPTP algorithm for overhead transmission lines is proposed on the basis of the above-mentioned analysis, as presented in Figure 11. The proposed MPTP includes the following steps:
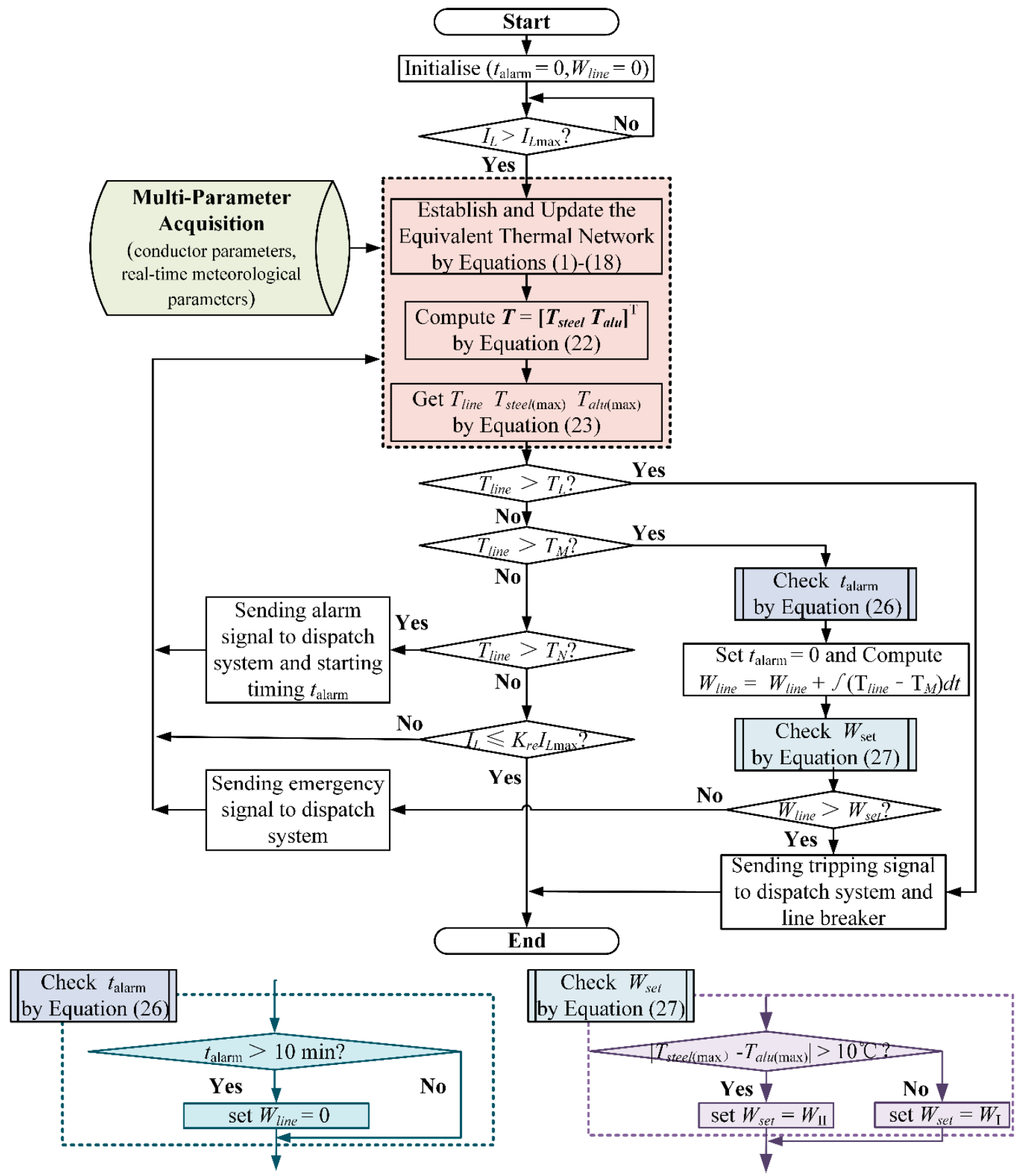

Figure 11. MPTP strategy flowchart of overhead transmission lines.

Step 1: Initialize $t_{\text {alarm }}$ and $W_{\text {line }}$ to 0 . Determine whether the operating current $I_{L}$ is greater than the maximum load current $I_{L \text { max }}$. Proceed to Step 2 when the start-up criterion of protection $I_{L}>I_{L \max }$ is satisfied.

Step 2: Obtain the meteorological parameters around the transmission line and conductor parameters. Then, modify the ETN in real-time by Equations (22) and (23), and calculate the transient temperature rise response. Proceed to Step 3. 
Step 3: Assess whether the calculated $T_{\text {line }}$ is greater than the limit temperature $T_{L}$. Send a trip signal to the dispatching system and the breaker of the transmission line to remove the line when criterion $T_{\text {line }}>T_{L}$ is satisfied. End the MPTP algorithm. Proceed to Step 4 when the $T_{\text {line }}$ does not exceed $T_{L}$.

Step 4: Determine whether the calculated $T_{\text {line }}$ is greater than the emergency temperature $T_{M}$. Otherwise, proceed to Step 5. Evaluate the $t_{\text {alarm }}$ using Equation (26) when criterion $T_{\text {line }}$ $>T_{M}$ is satisfied, and calculate the temperature-time integral $W_{\text {line }}$. Then, verify the emergency thermal setting value $W_{\text {set }}$ using Equation (27), and compare the values of $W_{\text {line }}$ and $W_{\text {set }}$. If the criterion $W_{\text {line }}>W_{\text {set }}$ is satisfied, a trip signal to the dispatching system and the breaker cuts off the line, and the algorithm ends. If the criterion $W_{\text {line }}>W_{\text {set }}$ is not satisfied, an emergency warning signal is sent to the dispatching system, and the algorithm returns to Step 2 to continue the calculation of transient temperature rise and thermal safety assessment for transmission line.

Step 5: Assess whether the calculated $T_{\text {line }}$ is greater than the alarm temperature $T_{N}$. Send an alarm signal to the dispatching system and start the $t_{\text {alarm }}$ when criterion $T_{\text {line }}>T_{L}$ is satisfied. Furthermore, return to Step 2. Proceed to Step 6 when criterion $T_{\text {line }}>T_{N}$ is unsatisfied.

Step 6: Determine whether operating current $I_{\mathrm{L}}$ is lower than return current $K_{r e} I_{L \max }\left(K_{r e}\right.$ is the return coefficient, generally set to 0.9$)$. End the protection algorithm when criterion $I_{L} \leq K_{r e} I_{L \max }$ is satisfied. Otherwise, return to Step 2, and continue the calculation of the transient temperature rise response and thermal safety assessment of the transmission line.

\section{Case Study for Protection of Overhead Transmission Lines}

\subsection{Test System}

In order to verify the validity and applicability of the above protection strategy, a simulation is carried out on the modified 29-bus test system (Hydro-Quebec) as shown in Figure 12.

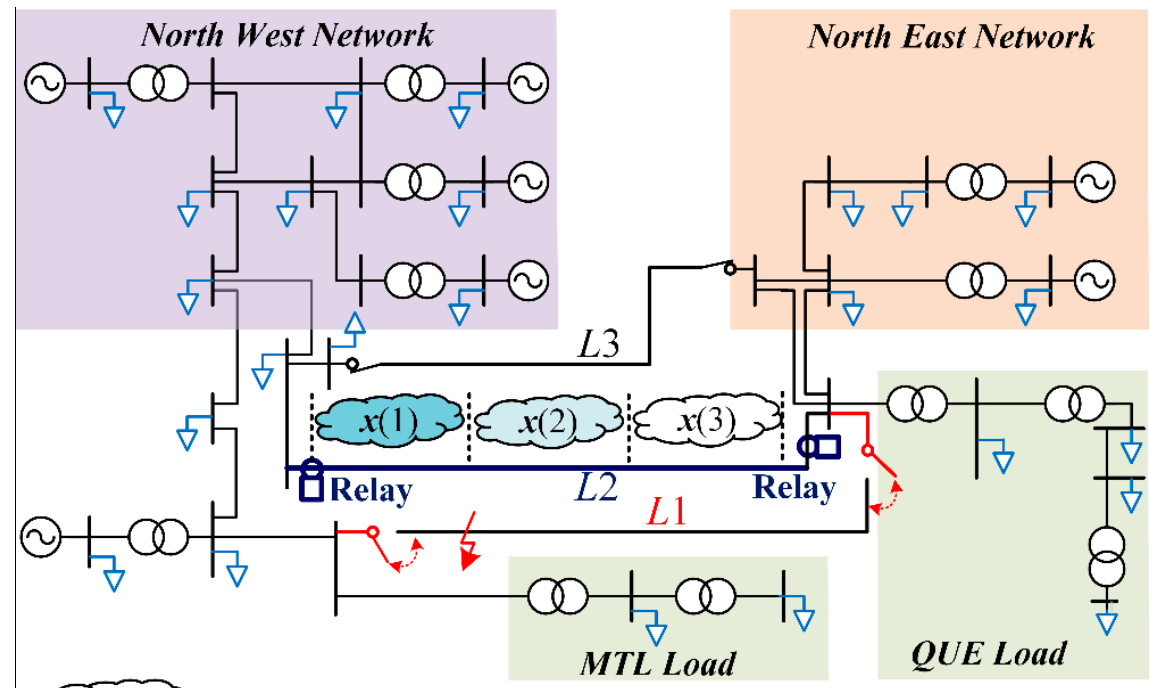

Ex(i), Meteorological Region $i=1,2,3$.

Figure 12. Modified 29-bus test system.

The detailed network parameters can be found in [39]. The system assumes that all lines are LGJ400/35. The conductor parameters are listed in Table A2.

In this case study, the MPTP is applied to Line $L 2$ to verify its feasibility and effectiveness. Considering that long-distance transmission lines span to different meteorological and geographical regions, Line $L 2$ is divided into three segments, that is, $N=3$. The main meteorological parameters are 
assumed to be known exactly and listed in Table 3, and the relevant meteorological parameters remain constant during overloading. On the basis of the conductor and meteorological parameters, the ETN of transmission lines is established in which $n=2, n_{s}=1$, and $n_{a}=1$.

Table 3. Parameters of meteorological regions.

\begin{tabular}{cccc}
\hline Regions & Air Temperature $\left({ }^{\circ} \mathbf{C}\right)$ & Wind Speed $^{\mathbf{1}}(\mathbf{m} / \mathbf{s})$ & Radiation Intensity $\left(\mathbf{W} / \mathbf{m}^{\mathbf{2}}\right)$ \\
\hline$x(1)$ & 30 & 4.0 & 800 \\
$x(2)$ & 35 & 2.0 & 1200 \\
$x(3)$ & 40 & 1.0 & 1000 \\
\hline
\end{tabular}

${ }^{1}$ It is assumed that the wind is vertical to the conductor in the case study.

\subsection{Results and Discussion}

The following situations are analyzed in the modified 29-bus test system (Hydro-Quebec).

Case I: Line $L 3$ is in a normal operation, Line $L 1$ trips at $t=120 \mathrm{~s}$ due to a fault, and Line $L 2$ is overloaded.

Case II: Line $L 3$ is disconnected due to maintenance, Line $L 1$ trips at $t=120 \mathrm{~s}$ due to a fault, and Line L2 is overloaded.

Case III:Line $L 3$ is disconnected due to maintenance, Line $L 1$ trips at $t=120 \mathrm{~s}$ due to a fault, and Line L2 is overloaded, which is in accordance with Case II. However, the power flow is adjusted by power system security and stability controls. Thus, the current of Line $L 2$ is reduced at $t=600 \mathrm{~s}$.

A specific analysis of the characteristics of MPTP in three cases is expressed as follows:

In Figure $13 \mathrm{a}$, the currents in all cases are greater in Line $L 2$ than the maximum load current. The start-up criterion of MPTP is satisfied, and the protection calculates and monitors the transient temperature rise of Line $L 2$. The calculated results of transient temperature rise response of Line $L 2$ during overloading after $t=120 \mathrm{~s}$ are plotted in Figure $13 \mathrm{~b}$.

In Case I, the transient temperature of Line $L 2$ does not exceed $T_{M}$ of $100{ }^{\circ} \mathrm{C}$ and $T_{L}$ of $120{ }^{\circ} \mathrm{C}$, thus indicating that Line $L 2$ is in a safe operation during overloading. However, the transient temperature of Line $L 2$ reaches $T_{N}$ of $70^{\circ} \mathrm{C}$ for the first time after $385 \mathrm{~s}$. Thus, the protection sends an alarm signal to the dispatching system at $t_{p a}=505 \mathrm{~s}$.

In Case II, the transient temperature of Line $L 2$ exceeds $T_{N}$ of $70{ }^{\circ} \mathrm{C}$ after $77 \mathrm{~s}$, exceeds $T_{M}$ of $100{ }^{\circ} \mathrm{C}$ after $308 \mathrm{~s}$, and exceeds $T_{L}$ of $120^{\circ} \mathrm{C}$ after $514 \mathrm{~s}$. On the basis of the protection strategy, the protection sends an alarm signal to the dispatching system at $t_{p a}=197 \mathrm{~s}$, sends an emergency signal to the dispatching system at $t_{p e}=428 \mathrm{~s}$, and calculates temperature-time integral $W_{\text {line }} . W_{\text {line }}$ does not exceed $W_{\text {set }}$ within the interval between $T_{M}$ of $100{ }^{\circ} \mathrm{C}$ and $T_{L}$ of $120^{\circ} \mathrm{C}$. The protection sends a trip signal to the dispatching system and the breaker to cut the line opportunely when the temperature exceeds $T_{L}$ of $120{ }^{\circ} \mathrm{C}$ at $t_{p t}=634 \mathrm{~s}$.

In Case III, the transient temperature of Line L2 is the same as Case II before the operation of security and stability controls. Therefore, the protection sends alarm and emergency signals to the dispatching system at $t_{p a}=197 \mathrm{~s}$ and $t_{p e}=428 \mathrm{~s}$, correspondingly. The line current is reduced with the effect of power system security and stability controls. The protection continues to monitor the transient temperature change trajectory during the operation of controls. The temperature-time integral $W_{\text {line }}$ is calculated. $W_{\text {line }}=4420^{\circ} \mathrm{C} \cdot \mathrm{s}$ in the range of $T_{M}$ of $100^{\circ} \mathrm{C}-T_{L}$ of $120^{\circ} \mathrm{C}$, which is lower than the thermal integral setting value $W_{\text {set }}$, and the temperature difference between the steel core and aluminum layer does not exceed $10^{\circ} \mathrm{C}$. Thus, the line can operate safely and stably.

Figure $13 \mathrm{c}$ depicts the relevant action signals of protection. MPTP-ALARM represents the line multi-parameter overload protection alarming signal, MPTP-EMER is the protection emergency signal, MPTP-TRIP is the protection tripping signal, and TOP-TRIP represents the line traditional overload 
protection tripping signal. The line is cut at $t_{p t}=120.2 \mathrm{~s}$ (after a short $0.2 \mathrm{~s}$ delay) for the three above-mentioned cases when the traditional overload protection is applied to Line L2. However, the action time of protection is increased by $513.8 \mathrm{~s}$ when the line adopts MPTP in Case II. In Cases I and III, the protection does not operate, but the alarm and emergency signals are sent to the dispatching system at $t_{p a}=197 \mathrm{~s}$ and $t_{p e}=428 \mathrm{~s}$, respectively, to ensure the safe and stable operation of the power grid after the fault.
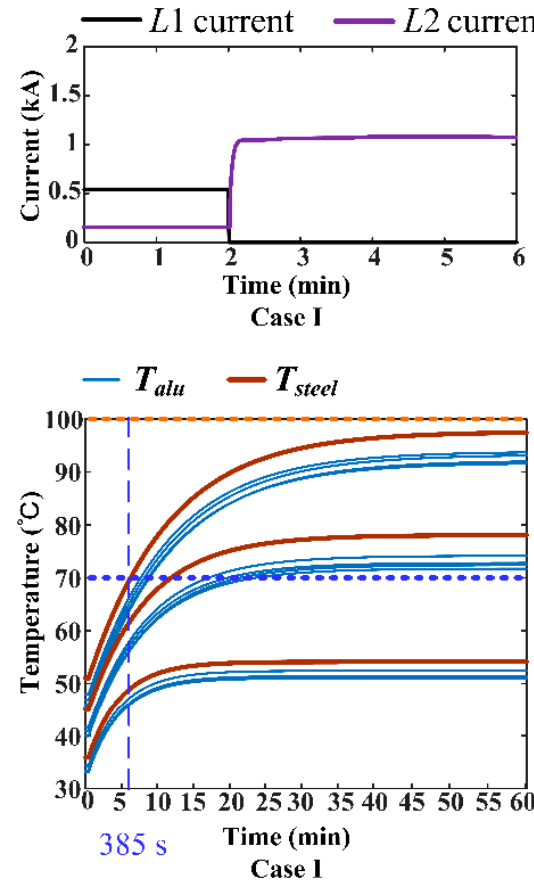

TOP-TRIP

MPTP-ALARM — MPTP-EMER —MPTP-TRIP

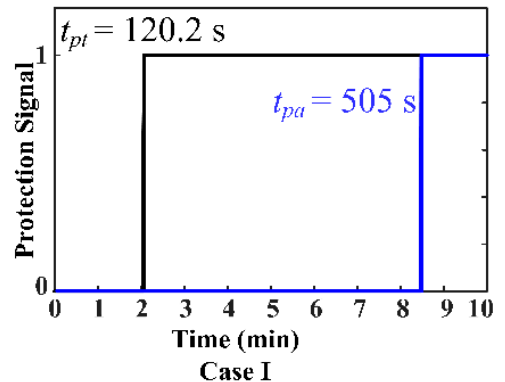

(c)
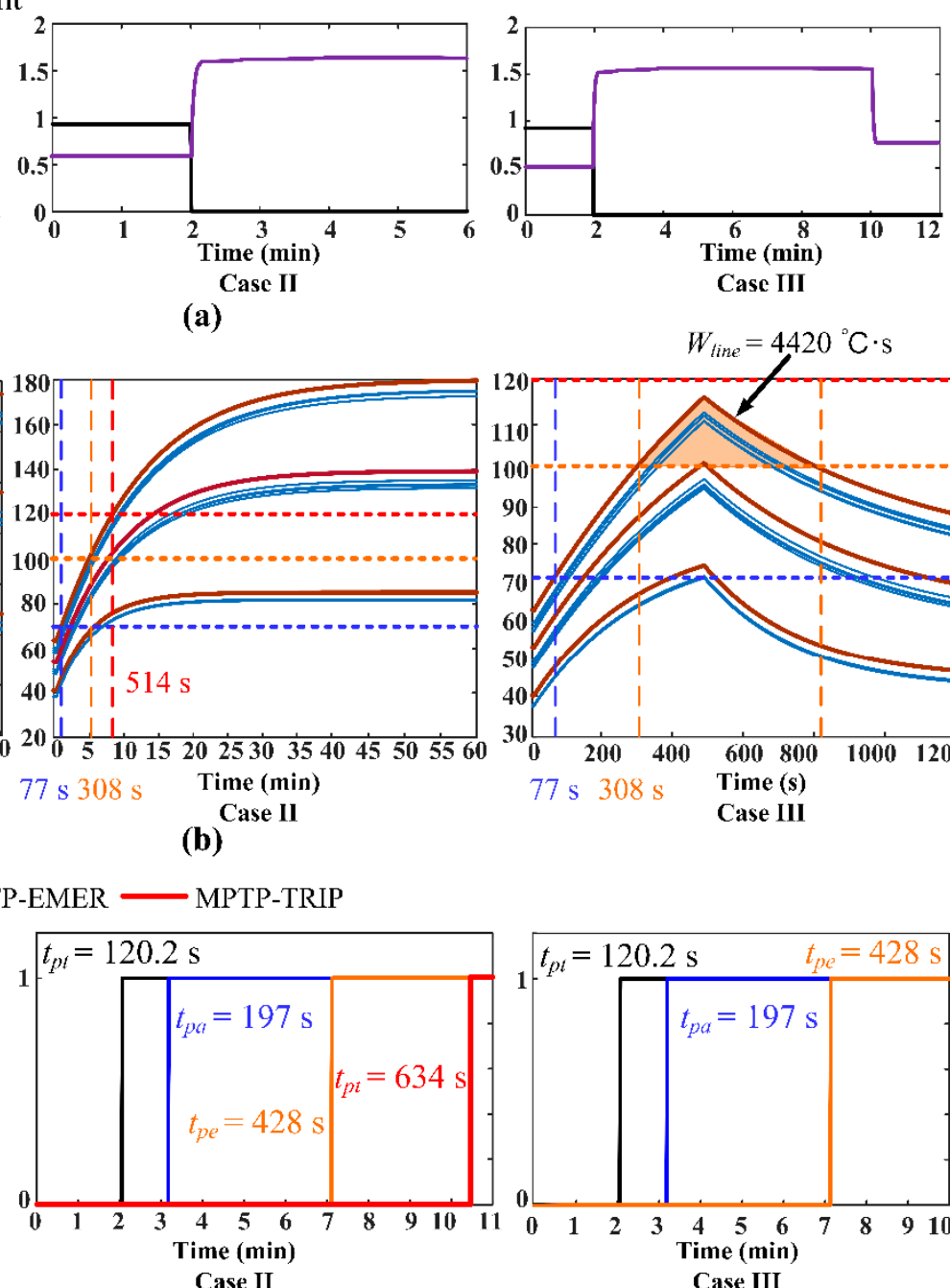

(a)
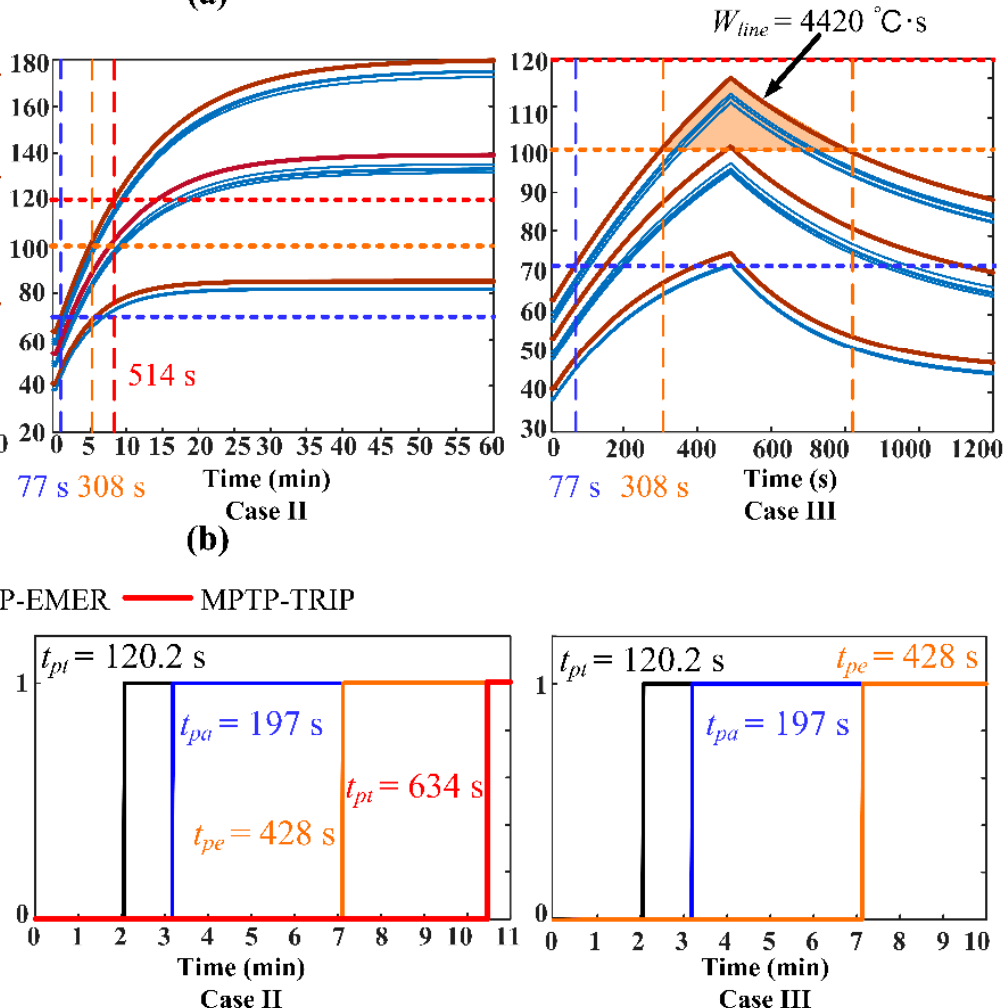

Case III

Figure 13. Simulation results of transmission line protection in three cases. (a) Current results; (b) temperature in different zones of the conductor cross-section; (c) Action signals of the MPTP and TOP.

On the basis of the above-mentioned simulation analysis, the MPTP of overhead transmission lines is different from the traditional overload protection. On the premise of ensuring safety, the MPTP of the line can maximize the ability of transmission lines to withstand overloading and maintain the integrity of the power grid. Thus, considerable time is available for the dispatching system to take measures, such as power flow adjustment and load shedding to eliminate overloading. Moreover, the protection can constantly monitor the transient temperature trajectory during overloading, and alarm and emergency signals are sent to the dispatching center appropriately to effectively prevent unnecessary trips and avoid accidents.

The MPTP calculation time is mainly affected by the values of $N, n_{\mathrm{s}}$, and $n_{\mathrm{a}}$. The average calculation time of the above-mentioned cases on an Intel i7 computer is approximately $170 \mathrm{ms,}$ 
which satisfies the engineering requirements. In actual projects, the calculation entails a reasonable selection of $N, n_{s}$, and $n_{a}$ values based on the meteorological distribution and conductor structure. Actual engineering application of the proposed protection and effective division method of meteorological regions are the future work. The effective use of the MPTP delay time to coordinate power system security and stability control measures also will be investigated in the future work.

\section{Conclusions}

This paper presented a transient temperature calculation method for overhead transmission lines based on ETN. This method was applied for overload protection to establish an MPTP strategy. This protection strategy could reflect the dynamic safety state of transmission lines well during overloading, which could effectively avoid cascading tripping and ensure the safe operation of a power grid. The following main conclusions were drawn from this study:

- Conductor cross-section heat transfers under overloading conditions can be characterized in three types, namely, radial and circumferential heat conduction, convection, and radiation. The ETN can integrate the above-mentioned types and simultaneously reflect the temperature-dependent characteristics of resistivity, thermal convection resistance, and radiant heat flux. The comparison of the calculated results with the experimental results shows that the calculation precision of the ETN is better than the IEEE and CIGRE standard models. The calculated relative error does not exceed $7.59 \%$ under $95 \%$ confidence interval.

- The transient temperature estimation of transmission lines based on ETN can objectively characterize the dynamic safety state of the entire line. In comparison with the DTLR, the proposed method can better reflect the effects of non-uniform meteorological distribution along the line and the different temperature rise responses in different parts of the transmission line.

- $\quad$ The MPTP of the transmission line can provide more time than the TOP when eliminating overloads. The delay time of the MPTP does not reduce transmission line security, which is derived from the electro-thermal coupling analysis of the line. The MPTP calculation time can satisfy the engineering requirements, as confirmed by the case study.

The finer temperature modelling and calculating of entire line under complicated environment (e.g., coupling between wind, rain, ice) will be researched in the follow-up study.

Author Contributions: In this research activity, J.H., X.X. and J.W. proposed the core idea and developed the models; J.H. and J.C. performed the simulations and analyzed the data; J.H. and W.W. contributed to the writing of this manuscript.

Funding: This work was supported by the National Key Research and Development Program of China (2016YFB0900600).

Conflicts of Interest: The authors declare no conflict of interest.

\section{Appendix A}

The specific parameters of submatrix $A_{j k}(j, k=1,2, \ldots, n)$ in Equation (4) are expressed as follows: where if $j=1, A_{1 k}=\left\{\begin{array}{cc}A_{11} & k=1 \\ A_{12} & k=2 \\ 0 & k=\text { else }\end{array}\right.$, if $j=2,3, \ldots, n-1, A_{j k}=\left\{\begin{array}{cc}A_{j j-1} & k=j-1 \\ A_{j j} & k=j \\ A_{j j+1} & k=j+1 \\ 0 & k=e l s e\end{array}\right.$, if $j=n$, $A_{n k}=\left\{\begin{array}{cc}A_{n n-1} & k=n-1 \\ A_{n n} & k=n \\ 0 & k=\text { else }\end{array}\right.$. 
By adopting the form of Equation (6), the corresponding elements of submatrix $A_{11}$ are:

$$
\left\{\begin{array}{l}
a_{11}^{A_{11}}=-\left(\frac{1}{C_{a 1} R_{h a}}+\frac{1}{C_{a 1} R_{r 1}}+\frac{2}{C_{a 1} R_{\lambda 1}}\right), a_{12}^{A_{11}}=a_{14}^{A_{11}}=\frac{1}{C_{a 1} R_{\lambda 1}} \\
a_{22}^{A_{11}}=-\left(\frac{1}{C_{b 1} R_{h b}}+\frac{1}{C_{b 1} R_{r 1}}+\frac{2}{C_{b 1} R_{\lambda 1}}\right), a_{21}^{A_{11}}=a_{23}^{A_{11}}=\frac{1}{C_{b 1} R_{\lambda 1}} \\
a_{33}^{A_{11}}=-\left(\frac{1}{C_{c 1} R_{h c}}+\frac{1}{C_{c 1} R_{r 1}}+\frac{2}{C_{c 1} R_{\lambda 1}}\right), a_{32}^{A_{11}}=a_{34}^{A_{11}}=\frac{1}{C_{c 1} R_{\lambda 1}} \\
a_{44}^{A_{11}}=-\left(\frac{1}{C_{d 1} R_{h d}}+\frac{1}{C_{d 1} R_{r 1}}+\frac{2}{C_{d 1} R_{\lambda 1}}\right), a_{42}^{A_{11}}=a_{43}^{A_{11}}=\frac{1}{C_{d 1} R_{\lambda 1}} \\
\text { Remaining elements are } 0
\end{array}\right.
$$

The corresponding elements of submatrix $A_{12}$ are:

$$
\left\{\begin{array}{l}
a_{11}^{A_{12}}=\frac{1}{C_{a 1} R_{r 1}}, a_{22}^{A_{12}}=\frac{1}{C_{b 1} R_{r 1}}, a_{33}^{A_{12}}=\frac{1}{C_{c 1} R_{r 1}}, a_{44}^{A_{12}}=\frac{1}{C_{d 1} R_{r 1}} . \\
\text { Remaining elements are } 0
\end{array} .\right.
$$

The corresponding elements of submatrix $A_{j j-1}$ are:

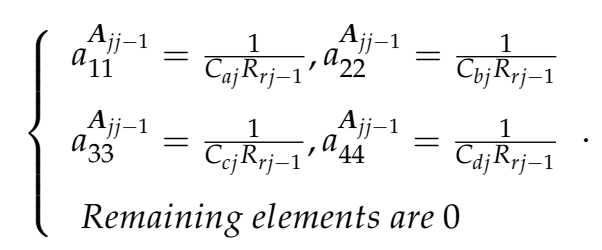

The corresponding elements of submatrix $A_{j j}$ are:

$$
\left\{\begin{array}{l}
a_{11}^{A_{j j}}=-\left(\frac{1}{C_{a j} R_{r j-1}}+\frac{1}{C_{a j} R_{r j}}+\frac{2}{C_{a j} R_{\lambda j}}\right), a_{12}^{A_{j j}}=a_{14}^{A_{j j}}=\frac{1}{C_{a j} R_{\lambda j}} \\
a_{22}^{A_{j j}}=-\left(\frac{1}{C_{b j} R_{r j-1}}+\frac{1}{C_{b j} R_{r j}}+\frac{2}{C_{b j} R_{\lambda j}}\right), a_{21}^{A_{j j}}=a_{23}^{A_{j j}}=\frac{1}{C_{b j} R_{\lambda j}} \\
a_{33}=-\left(\frac{1}{C_{c j} R_{r j-1}}+\frac{1}{C_{c j} R_{r j}}+\frac{2}{C_{c j} R_{\lambda j}}\right), a_{32}=a_{34}=\frac{1}{C_{c j} R_{\lambda j}} \\
a_{44}^{A_{j j}}=-\left(\frac{1}{C_{d j} R_{r j-1}}+\frac{1}{C_{d j} R_{r j}}+\frac{2}{C_{d j} R_{\lambda j}}\right), a_{42}^{A_{j j}}=a_{43}=\frac{1}{C_{d j} R_{\lambda j}} \\
\text { Remaining elements are } 0
\end{array}\right.
$$

The corresponding elements of submatrix $A_{j j+1}$ are:

$$
\left\{\begin{array}{c}
a_{11}^{A_{j j+1}}=\frac{1}{C_{a j} R_{r j}}, a_{22}^{A_{j j+1}}=\frac{1}{C_{b j} R_{r j}} \\
a_{33}^{A_{j j+1}}=\frac{1}{C_{c j} R_{r j}}, a_{44}^{A_{j j+1}}=\frac{1}{C_{d j} R_{r j}} \\
\text { Remaining elements are } 0
\end{array} .\right.
$$

All the elements in submatrix $A_{n n-1}$ are $1 /\left(C_{f} R_{r n-1}\right)$, and $A_{n n}=\left(-4 /\left(C_{f} R_{r n-1}\right)\right) \operatorname{diag}(1,1,1,1)$.

\section{Appendix B}

Table A1 show that the main parameters of the experimental equipment in temperature rise test platform. Table A2 show that the main parameters of ACSR LGJ400/35 conductor. 
Table A1. Main parameters of experimental equipment in temperature rise test platform.

\begin{tabular}{|c|c|c|}
\hline Name & Model Number & Main Specification \\
\hline Steel frame & Self-made & $\begin{array}{l}\quad 0.8 \times 0.8 \times 2.0 \mathrm{~m} \\
\text { Rated capacity: } 30 \mathrm{kVA}\end{array}$ \\
\hline Large current generator & SDDL-5000Q & $\begin{array}{l}\text { Output current: } 0-5000 \mathrm{~A} \\
\text { Accuracy: } 0.1 \%\end{array}$ \\
\hline Controllable blower & HB-429 & $\begin{array}{l}\text { Wind speed: } 0-10 \mathrm{~m} / \mathrm{s} \\
\text { Ratio: } 3200 / 5 \mathrm{~A}\end{array}$ \\
\hline Current transformer & LXZK-0.66 & $\begin{array}{l}\text { Rated Burden: } 15 \mathrm{VA} \\
\text { Accuracy: } 0.2 \%\end{array}$ \\
\hline Temperature sensor & PT1000 & $\begin{array}{c}\text { Range: }-70^{\circ} \mathrm{C}-+500^{\circ} \mathrm{C} \\
\left.\text { Accuracy: } \pm 0.03^{\circ} \mathrm{C} \text { (class } 1 / 10 \mathrm{~B}\right)\end{array}$ \\
\hline Ultrasonic anemometer & HY-WDS3 & $\begin{array}{l}\text { Range: } 0-60 \mathrm{~m} / \mathrm{s}, 0-359^{\circ} \\
\text { Resolution: } 0.01 \mathrm{~m} / \mathrm{s}, 0.1^{\circ}\end{array}$ \\
\hline $\begin{array}{l}\text { Radiation intensity } \\
\text { measuring instrument }\end{array}$ & SPN1 & $\begin{array}{l}\text { Range: } 0-2000 \mathrm{~W} / \mathrm{m}^{2} \\
\text { Resolution: } 0.6 \mathrm{~W} / \mathrm{m}^{2}\end{array}$ \\
\hline $\begin{array}{l}\text { Multi-channel data } \\
\text { acquisition device }\end{array}$ & Agilent 34970A \& 34901A & $\begin{array}{l}\text { Scan rate: } 250 \text { Channels/s } \\
\text { Resolution: } 22 \text { bits }\end{array}$ \\
\hline
\end{tabular}

Table A2. Main parameters of ACSR LGJ400/35 conductor.

\begin{tabular}{cc}
\hline Parameter & Value \\
\hline Conductor outside diameter $D_{0}(\mathrm{~mm})$ & 26.82 \\
Steel core diameter $(\mathrm{mm})$ & 7.5 \\
Aluminum outer strand diameter $(\mathrm{mm})$ & 3.22 \\
Sectional area $\left(\mathrm{mm}^{2}\right)$ & 425.24 \\
Emissivity ${ }^{1}$ & 0.9 \\
Solar absorptivity $\delta$ & 0.9 \\
Steel specific heat capacity at $20{ }^{\circ} \mathrm{C}, c_{\mathrm{S}}\left(\mathrm{J} / \mathrm{kg} \cdot{ }^{\circ} \mathrm{C}\right)$ & 481 \\
Aluminum specific heat capacity at $20{ }^{\circ} \mathrm{C}, \mathrm{c}_{\mathrm{a}}\left(\mathrm{J} / \mathrm{kg} \cdot{ }^{\circ} \mathrm{C}\right)$ & 897 \\
Steel mass per unit length, $m_{\mathrm{S}}(\mathrm{kg} / \mathrm{m})$ & 0.267 \\
Aluminum mass per unit length, $m_{\mathrm{a}}(\mathrm{kg} / \mathrm{m})$ & 1.079 \\
Mass per unit length of steel $(\mathrm{kg} / \mathrm{m})$ & 1.349
\end{tabular}

${ }^{1}$ The new or light conductor emissivity $\varepsilon$ is in the range of $0.2-0.5$; the old or black conductor emissivity $\varepsilon$ is in the range of $0.9-0.95 ;^{2}$ the conductor solar absorptivity $\delta$ is in the range of $0.2-0.95$.

\section{References}

1. Abdullah, A.M.; Butler, K. Distance protection zone 3 misoperation during system wide cascading events: The problem and a survey of solutions. Electr. Power Syst. Res. 2018, 154, 151-159. [CrossRef]

2. Ebrahim, V. Practical Power System Operation; Wiley-IEEE: Upper Saddle River, NJ, USA, 2014; ISBN 9781118394021.

3. Bakar, A.A.; Yatim, F.M.; Yusof, S.; Othman, M.R. Analysis of overload conditions in distance relay under severe system contingencies. Int. J. Electr. Power Energy Syst. 2010, 32, 345-350. [CrossRef]

4. Pavlatos, C.; Vita, V. Linguistic representation of power system signals. In Electricity Distribution; Energy Systems Series; Springer: Berlin/Heidelberg, Germany, 2016; pp. 285-295. [CrossRef]

5. Andersson, G.; Donalek, P.; Farmer, R. Causes of the 2003 major grid blackouts in North America and Europe, and recommended means to improve system dynamic performance. IEEE Trans. Power Syst. 2005, 20, 1922-1928. [CrossRef]

6. Dong, X.; Cao, R.; Wang, B.; Shi, S.; Bak, D. India blackout and three functions of protective relay. Power Syst. Prot. Control 2013, 41, 19-25. [CrossRef]

7. Rosas, C.M.; Sole, R. Analysis of major failures in Europe's power grid. Int. J. Electr. Power Energy Syst. 2011, 33, 805-808. [CrossRef]

8. Dong, X. Analytic method to calculate and characterize the sag and tension of overhead lines. IEEE Trans. Power Del. 2016, 31, 2064-2071. [CrossRef] 
9. Cooper, I.P.; Kopsidas, K.; Boumecid, B. Overhead line design considerations for conductor creep mitigation. IET Gener. Transm. Distrib. 2016, 10, 2424-2432. [CrossRef]

10. IEEE. IEEE Std 1283-2013: IEEE Guide for Determining the Effects of High-Temperature Operation on Conductors, Connectors, and Accessories; IEEE Standard Association: Washington, DC, USA, 2013. [CrossRef]

11. Wang, Y.; $\mathrm{Xu}, \mathrm{W}$; Shen, J. Online tracking of transmission-line parameters using SCADA data. IEEE Trans. Power Del. 2016, 31, 674-682. [CrossRef]

12. Douglass, D.; Chisholm, W.; Davidson, G.; Grant, I.; Lindsey, K.; Lancaster, M.; Lawry, D.; McCarthy, T.; Nascimento, C.; Pasha, M.; et al. Real-time overhead transmission-line monitoring for dynamic rating. IEEE Trans. Power Deliv. 2016, 31, 921-927. [CrossRef]

13. Zhou, Z.; Wang, X.; Du, D.; Li, Y.; Li, M. A coordination strategy between relay protection and stability control under overload conditions. Proc. CSEE 2013, 33, 146-155.

14. Cong, Y.; Regulski, P.; Wall, P.; Osborne, M.; Terzija, V. On the use of dynamic thermal-line ratings for improving operational tripping schemes. IEEE Trans. Power Del. 2016, 31, 1891-1990. [CrossRef]

15. Staszewski, Ł.; Rebizant, W. DLR-supported overcurrent line protection for blackout prevention. Elect. Power Syst. Res. 2018, 155, 104-110. [CrossRef]

16. Carneiro, J.; Ferrarini, L. A probabilistic protection against thermal overloads of transmission lines. Electr. Power Syst. Res. 2011, 81, 1874-1880. [CrossRef]

17. IEEE. IEEE Std 738-2012: IEEE Standard for Calculating the Current-Temperature Relationship of Bare Overhead Conductors; IEEE Standard Association: Washington, DC, USA, 2013.

18. CIGRE Working Group B2. 42. Guide for Thermal Rating Calculations of Overhead Lines; Technical Brochure 601; CIGRE: Paris, France, 2014; Available online: https: / /e-cigre.org/publication/601-guide-for-thermalratingcalculations-of-overhead-lines (accessed on 15 August 2018).

19. Arroyo, A.; Castro, P.; Martinez, R.; Manana, M.; Madrazo, A.; Lecuna, R.; Gonzalez, A. Comparison between IEEE and CIGRE thermal behavior standards and measured temperature on a 132-kV overhead power line. Energies 2015, 8, 13660-13671. [CrossRef]

20. Sugihara, H.; Funaki, T.; Yamaguchi, N. Evaluation method for real-time dynamic line ratings based on line current variation model for representing forecast error of intermittent renewable generation. Energies 2017, 10, 503. [CrossRef]

21. Alvarez, D.L.; Silva, F.M.F.D.; Mombello, E.E.; Bak, C.L.; Rosero, J.A. Conductor temperature estimation and prediction at thermal transient state in dynamic line rating application. IEEE Trans. Power Deliv. 2018, 33, 2236-2245. [CrossRef]

22. Sarajlić, M.; Pihler, J.; Sarajlić, N.; Štumberger, G. Identification of the heat equation parameters for estimation of a bare overhead conductor's temperature by the differential evolution algorithm. Energies 2018, 11, 2061. [CrossRef]

23. Chatzipanagiotou, P.; Chatziathanasiou, V. Dynamic thermal analysis of a power line by simplified RC model networks: Theoretical and experimental analysis. Int. J. Electr. Power Energy Syst. 2019, 106, 288-293. [CrossRef]

24. Liu, G.; Rung, B.; Zhnag, M. A transient model for overhead transmission line dynamic rating based on thermal circuit method. Autom. Electr. Power Syst. 2012, 16, 58-62. [CrossRef]

25. Liu, G.; Ruan, B.; Lin, J.; Yang, M.; Zhang, M.; Xu, Z. Steady-state model of thermal circuit method for dynamic overhead lines rating. High Voltage Eng. 2013, 39, 1107-1113. [CrossRef]

26. Zhang, X.; Ying, Z.; Chen, Y.; Chen, X. A thermal model for calculating axial temperature distribution of overhead conductor under laboratory conditions. Elect. Power Syst. Res. 2019, 166, 223-231. [CrossRef]

27. Ying, Z.; Du, Z.; Feng, K.; Liu, Y.; Wu, J. Radial thermal circuit model and parameter calculation method for high voltage overhead transmission line. Trans. Chin. Electrotech. Soc. 2016, 31, 13-21.

28. Ying, Z.; Kai, F.; Du, Z.; Liu, Y.; Wu, J. Thermal circuit modeling of the relationship between current and axial temperature for high voltage overhead conductor. Proc. CSEE 2015, 35, 2887-2895. [CrossRef]

29. Makhkamova, I.; Mahkamov, K.; Taylor, P. CFD thermal modelling of Lynx overhead conductors in distribution networks with integrated renewable energy driven generators. Appl. Thermal Eng. 2013, 58, 522-535. [CrossRef]

30. Farzaneh, M.; Farokhi, S.; Chisholm, W. Electrical Design of Overhead Power Transmission Lines; McGraw-Hill: New York, NY, USA, 2012; ISBN 9780071771917.

31. Stephan, K. Heat and Mass Transfer; Springer: Singapore, 2017; ISBN 9783540295266. 
32. Cotton, I.; The, J. Critical span identification model for dynamic thermal rating system placement. IET Gener. Transm. Distrib. 2015, 16, 2644-2652. [CrossRef]

33. Greenwood, D.M.; Gentle, J.P.; Myers, K.S.; Davison, P.J.; West, I.J.; Bush, J.W.; Ingram, G.L.; Troffaes, M.C. A comparison of real time thermal rating systems in the U.S. and the UK. IEEE Trans. Power Deliv. 2014, 29, 1849-1858. [CrossRef]

34. Lo, C.F.; Yang, Z.L.; Pielke, R.A. Assessment of three dynamical climate downscaling methods using the Weather Research and Forecasting (WRF) model. J. Geophys. Res. 2008, 13, 91-112. [CrossRef]

35. Verbois, H.; Huva, R.; Rusydi, A.; Walsh, W. Solar irradiance forecasting in the tropics using numerical weather prediction and statistical learning. Solar Energy 2018, 162, 265-277. [CrossRef]

36. China Association for Engineering Construction Standardization, CECS. Load Code for the Design of Building Structure; China Architecture Building Press: Beijing, China, 2012; ISBN 9787112071050.

37. Yi, D.; Yangchun, C.; Wanli, Z.; Jiedong, L. Dynamic Capacity Increasing Technology of High Voltage Overhead Transmission Line; China Electric Power Press: Beijing, China, 2013; ISBN 9787512341951.

38. CIGRE Working Group B2. 42. Guide to the Operation of Conventional Conductor Systems above $100{ }^{\circ} \mathrm{C}$; Technical Brochure 643; CIGRE: Paris, France, 2015; Available online: https: / / e-cigre.org/publication/643-guide-tothe-operation-of-conventional-conductor-systems-above-100c (accessed on 15 August 2018).

39. The Mathworks. Initializing a 29-Bus 7-Power Plant Network with the Load FlowTool of Powergui. 2018. Available online: https://ww2.mathworks.cn/help/physmod/sps/examples/initializing-a-29-bus7-power-plant-network-with-the-load-flow-tool-of-powergui.html (accessed on 15 August 2018).

(C) 2018 by the authors. Licensee MDPI, Basel, Switzerland. This article is an open access article distributed under the terms and conditions of the Creative Commons Attribution (CC BY) license (http:/ / creativecommons.org/licenses/by/4.0/). 